(Hygiene-Institut der Univ. Marburg, Direktor : Prof. SiEgERT) während der entsprechenden Zeit; c) der Nachweis eines Agens im Bläscheninhalt; d) Titeranstiege zum isolierten Agens bei einem Teil der Patienten, die darauf hindeuten, daß zumindest bei ihnen Krankheitserscheinungen und Virusinfektion parallel verliefen."

Der Isolierung von ECHO-Viren aus dem Bläscheninhalt messen auch MUNK und NAShmann (1959) größere Bedeutung bei als der Züchtung aus Stuhlproben heraus. Die in Deutschland im Herbst 1958 beobachtete Epidemie zeigte gewisse Parallelen zum Bostoner Exanthem (1951). Der Erreger der „Boston exanthema disease" war aber das ECHO-16-Virus, das in Deutschland von keinem Untersucher gefunden wurde. Andererseits hatte das Exanthema infectiosum variabile, wie es in Deutschland gesehen wurde, keine zwingende Ähnlichkeit mit dem ECHO-4. Exanthem, wie es SABIN (1958) beschrieb. Geprüft werden muß noch, ob das von Munk und Naskmann (1959) gezüchtete Virus mit dem Serotyp 4 völlig identisch oder nur eng verwandt (evtl. ein neuer Typ?) ist. Befriedigend stimmte das Exanthem in Deutschland auch klinisch-morphologisch nicht mit dem Bostoner Exanthem überein, ebensowenig wie mit den Hauterscheinungen bei den Infektionen durch die Typen 4, 6 und 9 der ECHO-Viren. Geklärt ist demnach die Ätiologie des Exanthema infectiosum variabile noch nicht.

\title{
IV. Exanthematische Viruskrankheiten aus dem Grenzgebiet der Dermatologie
}

\section{Einleitung, Hinweise auf die Darstellungen im Jadassohnschen Handbuch (1930-1932)}

Im folgenden Kapitel werden Viruskrankheiten besprochen, die zwar Haut- und Schleim. hautveränderungen verursachen, doch nur zum Grenzgebiet der Dermatologie gerechnet werden können. Es handelt sich im wesentlichen um „Akute Exantheme“, die zur Domäne der Pädiatrie, der Inneren und Tropen-Medizin gehören. Gelegentlich suchen Erwachsene (und auch Kinder) mit Masern, Röteln oder Ringelröteln den Dermatologen auf, da die Hautveränderungen das Hauptsymptom der Erkrankungen sein können. Es ist daher notwendig, bei der Abhandlung dieses Grenzgebietes besonders die Differentialdiagnose zu berücksichtigen. Gesamtdarstellungen der akuten Exanthemkrankheiten des Kindesalters und der in Subtropen und Tropen heimischen Virusinfektionen mit Hauterscheinungen (Rash-artige Exantheme) können hier nicht gegeben werden (es sei daher auf die Handbücher der betreffenden Fächer verwiesen). Das Hauptanliegen der folgenden Ausführungen ist es, dem Dermatologen einige Hinweise auf die modernen Entwicklungen innerhalb dieses Grenzgebietes, vor allem auf den Sektoren der Diagnostik (moderne Laboratoriumsmethoden), der Therapie und der Prophylaxe (passive und aktive Schutzimpfungen) zu vermitteln. Die im Rahmen dieses Kapitels besprochenen, mit Hauterscheinungen einhergehenden Krankheiten zählen zu den sog. "Klassischen Exanthemen", hingegen werden die im vorhergehenden Abschnitt erörterten, durch Enteroviren verursachten Infektionen mit Rash-ähnlichen Hautveränderungen und Schleimhautläsionen als „Neue Exanthemkrankheiten" bezeichnet. Da ein Teil der letzteren (z.B. das Bostoner Exanthem, die Herpangina und vielleicht das Exanthema infectiosum variabile) sicher zum Fachgebiet der Dermatologie gehören, wurden sie nicht in dieses Kapitel aufgenommen, sondern unabhängig davon beschrieben.

Im alten Jadassohnschen Handbuch wurden die akuten Exantheme aus unterschiedlichem Blickwinkel von mehreren Autoren dargestellt, und zwar von LIPSCHÜTz (1932) im Band II: Masern, Röteln, Pappataci- und Dengue- sowie Gelbfieber (Kapitelanfänge: S. 108, 115, 157, 159), von JADASSOHN (1932) ebenfalls im Band II : Scharlach und Masern (S. 403, 416: Immun. biologie), von MAYER (1932) im Band XII, Teil 1 : Dengue- und Pappatacifieber (S. 208, 209), von MoraWeTz (1930) im Band XIV, Teil 1: Scharlach, Masern, Röteln, Rubeola scarlatinosa (4. Krankheit) und Erythema infectiosum (S. 419, 424, 427, 429, 454) und von LEINER im gleichen Band das Exanthema subitum (Roseola infantum, S. 473). In diesen zahlreichen Abhandlungen ist vor allem die Klinik der einzelnen Krankheitsbilder in auch heute noch gültiger Weise geschildert. Im folgenden kann daher auf klinische Details fast völlig verzichtet werden. 


\section{Masern}

\section{a) Synonyma}

Morbilli, Measles, Rougéole, Sarampión, Morbillo, Kanyaró.

\section{b) Definition}

„Die hohe Kontagiosität der Pocken und der Varicellen wird von den Masern noch übertroffen" (NAUCK 1958). Kontagionsindex: 96\%. Masern sind weltweit verbreitet und eine oft schwere kindliche Infektionskrankheit. Die Inkubationszeit ist streng normiert und beträgt 11-14 Tage (selten Abweichungen davon in Grenzen von 9-19 Tagen). Masern besitzen einen diphasischen Verlauf mit einem katarrhalischen Vorstadium, in dem ,pathognomonische weiße Flecken auf der Wangenschleimhaut" (Kopliksche Flecken: wichtig für die Diagnose!) auftreten - und mit einem ,nachfolgenden typischen maculopapulösen Exanthemstadium" (GERMER 1954). Die Prognose der nicht-komplizierten Masern ist gut. Die früher gefürchteten Komplikationen durch bakterielle Sekundärinfektionen (Otitis media, Pneumonien usw.) werden heute durch Antibiotica und Sulfonamide beherrscht oder verhindert. Ernst zu beurteilen (10\% Letalität) ist die MasernEncephalitis. Durch das Masernvirus selbst bedingte Pneumonien kommen vor. Masern sind in größeren Bevölkerungsgruppen endemisch (größere Epidemien alle 2-3 Jahre). Im Alter von 20 Jahren hat $90 \%$ der Bevölkerung bereits Masern durchgemacht (BLANK und RAKE 1955). Säuglinge verfügen in den ersten 3 bis 4 Monaten über eine passive (diaplacentar erworbene) Immunität. Abortive Masernverläufe sind selten (1-2\%; Germer 1954). Die Krankheit hinterläßt eine dauerhafte Immunität. Zweiterkrankungen sind sehr selten. Schwangere Frauen, die an Masern erkranken, abortieren häufig (NAUck 1958). Ob es eine Masern-Fmbryopathie im selben Sinne wie bei Rubeolen gibt, ist fraglich (Literatur s. bei Flam 1959) und wird von manchen Autoren verneint.

Die Maserninfektion erfolgt auf dem Wege über die Schleimhaut durch direkten Kontakt oder Tröpfcheninfektion. Das Masernvirus verbreitet sich auf dem Blutwege (schon am 3. Tage Virämie experimentell nachgewiesen; Dauer und Ausmaß der sekundären Virämie - während des Exanthems - sind für die Ausbildung der langdauernden Immunität verantwortlich). Das Virus-haltige Blut kann mit Erfolg auf Versuchspersonen übertragen werden. Im Prodromalstadium kommt es zu einer Hyperplasie des lymphatischen Gewebes (Lymphknoten, Tonsillen, Milz, Appendix, Peyersche Plaques im Dünndarm) und zum Auftreten der WarthinFinkeldeyschen Riesenzellen (WARTHIN 1931). Analoge Riesenzellbildungen sieht man nach Infektion von Gewebekulturen mit dem Masernvirus. Den charakteristischen Riesenzellen kommt ein gewisser diagnostischer Wert zu, da sie z. B. auch im Nasensekret während des Prodromalstadiums nachgewiesen werden können (u. a. Meuli 1955 sowie Haneke 1957). - Ockuttz und NeuendorfF (1958) halten hingegen den differentialdiagnostischen Wert des Riesenzellennachweises für gering.

Histologisch findet man bei Masern zu Beginn des Exanthems eine Hyperämie und vor allem in den tieferen Schichten der Cutis (bis in die Subcutis) ein Ödem. Keine stärkeren perivasculären Infiltrate; Endothelschwellungen sind häufig vorhanden. In der Epidermis können die Zellkerne im Stratum Malpighii vacuolisiert sein, außerdem bilden sich ein intracelluläres Ödem und subepitheliale Infiltrate aus Lymphocyten, epithelialen Zellen, polynucleären Leukocyten und Zellen mit Paarkernen (Abschwemmung der degenerierten Epidermiszellen in die Cutis, Umwandlung in homogene, kugelige Gebilde, aus denen der Nucleus verschwindet: „desquamativer Hautkatarrh" nach ABRAmow 1921). Details s. bei Gans und Steigleder (1957). 


\section{c) Differentialdiagnose}

Im Prodromalstadium der Masern (mit katarrhalischen Erscheinungen, Conjunctivitis, Nasenbluten) kann ,der Eingang der verstopften Nase sowie die angrenzende Oberlippe durch die macerierenden Exsudate erodiert und gegebenenfalls ulceriert werden" (SCHUERMANN 1958). OxENIUS (1941) beobachtete zuweilen rüsselförmige Schwellungen der Lippen, die den Verdacht auf Lippenfurunkel erweckten, jedoch in 2 bis 3 Tagen wieder abklangen (,Masernlippe“). Außerdem stellen sich bei Masern gern diffuse, hellrote Enantheme im Bereich der Rachenund Wangenschleimhaut ein.

Differentialdiagnostisch wichtig (z. B. für die Abgrenzung gegen Rubeolen und Scharlach) sind die am 2. oder 3. Tag (seltener etwas später) des Prodromalstadiums sich entwickelnden Koplikschen Flecke. Sie siedeln sich meist bilateral um die Mündung des Ductus parotidicus, gegenüber den Praemolaren und auch an der Unterlippenschleimhaut — oft gruppiert — an (bei etwa $90 \%$ der Fälle). Es handelt sich um 1 bis $3 \mathrm{~mm}$ große, gelblich-weißliche (zuweilen mit einem Stich ins Bläuliche), leicht erhabene Stippchen mit rotem Rand, denen 6 Stunden bis zu 4 Tage später die Eruption des Exanthems folgt (SchuERManN 1958). Ebenfalls meist kurz vor dem Exanthem schießen dunkelrote Flecke im Bereich von weichem und hartem Gaumen, von Vulva und Tonsillen auf. Dieses fleckförmige Enanthem ist zusammen mit den Koplikschen Flecken für die Erkennung der Masern bedeutungsvoll. Ähnliche Flecken sind mitunter an den Conjunctiven zu sehen (BLANK und RAKE 1955, seltener Cornealgeschwüre).

Das fleckförmige Masernexanthem wird später erhaben; die Flecken bekommen jedoch weniger eine papulöse Beschaffenheit, sondern nehmen mehr eine urticarielle Note an. Diese exsudative Komponente ist gelegentlich so stark ausgeprägt, daß sich im Zentrum der urticariellen Flecke kleinste, miliare Bläschen zu bilden vermögen (Morbilli vesiculosi). Bei sehr schwerem Krankheitsverlauf kann das Exanthem hämorrhagisch werden. DEGEN (1951) beobachtete sogar bei einem abortiv verlaufenden Masernfall Hämorrhagien im Gesicht und am Hals.

Am häufigsten ist eine Abtrennung der Masern von Scharlach und Röteln notwendig. Der Scharlach hat im Gesicht keine fleckförmige Beschaffenheit und zeigt eine periorale Blässe (Masernflecken auch um den Mund herum). Eine gute Hilfe stellt der Debré-Test dar (Aussparphänomen). Wird Masernrekonvaleszenten-Serum intradermal injiziert, so wird die Injektionsstelle von einem Masernexanthem nicht befallen - (Parallele: Auslöschphänomen nach SCHULTZ-CHARLTON beim Scharlach).

Rubeolen verlaufen im allgemeinen milder als Masern, weisen meist geringere katarrhalische Erscheinungen auf und deutliche Lymphknotenschwellungen am hinteren Rande des Musculus sternocleidomastoideus und im Nacken. Bei Röteln ungewöhnliche, bei keiner anderen Infektionskrankheit in dieser Weise auftretende Vermehrung der Plasmazellen bis zu 12\% (zuweilen bis zu $34 \%$ !), bei Masern meist geringe Leukopenie mit Verminderung der Lymphocyten und der Eosinophilen.

Morbilliforme Exantheme kommen weiter bei der Dengue, der Mononucleosis infectiosa und Arzneimittelallergien sowie bei der Lues II (Wassermann-Reaktion, Spirochäten-Eiweißreaktion, evtl. Nelsontest) vor. Über Dengue und Mononucleasis s. weiter unten!

\section{d) Laboratoriumsdiagnose}

Bereits 1911 wiesen ANDERson und GoLDBERGER nach, daß ultrafiltriertes, infektiöses Material von Masernkranken auf Affen übertragen werden kann. Bei ausgedehnten Affenversuchen der letzten Jahre fiel auf, daß bei manchen Tieren 
keine Krankheitserscheinungen hervorgerufen werden konnten, da sie bereits gegen das Masernvirus gerichtete Antikörper im Blutserum besaßen! Erklärt wurde dieser Vorgang durch die Isolierung eines Agens aus Nierengewebe scheinbar gesunder Affen, das mit dem Masernvirus identisch war (ENDERS-RuckLE 1960). Noch steht nicht fest, ob das bei Affen gefundene Masernvirus auf diese Tiere im Laufe ihrer Gefangenschaft zufällig übertragen wurde, oder ob bei Affen „,eine spezieseigene Erkrankung“" vorkommt - etwa in der gleichen Art, wie es bei den Beziehungen zwischen Masern- und dem Hundestaupe-Virus zu sein scheint (gemeinsame antigene Komponenten bei Masern- und Staupevirus, Adams und ImaGawa 1957).

Das Masernvirus kann in Bruteiern (Chorionallantoismembran) zur Vermehrung gebracht werden (WENCKEBACH 1938, RAKE und SHAFFER 1939 u. a.). Es gelang auch, dieses Virus (z. B. nach Anzüchtung in HeLa-Zellkulturen) mittels intracerebraler Inoculation auf Babymäuse zu übertragen (IMAGAWA und ADAMS 1958). Das bedeutendste Tsolierungsverfahren ist aber die Züchtung in Zellkulturen.

Die erste Züchtung des Masernvirus in Gewebekulturen aus Affennierenepithel und aus Zellen menschlicher Abkunft führten ENders und PeEBLEs (1954) durch. In den Kulturen entstanden 2 bis 7 Tage nach der Beimpfung syncytiale Zellkomplexe, die zwischen 40 und 100 Kerne aufwiesen und deren Cytoplasma vacuolisiert war (multinucleäre Riesenzellen). Dieser cytopathogene Effekt setzte herdförmig ein und dehnte sich langsam über den ganzen Zellrasen aus. Später zerfielen diese riesigen Zellaggregate. In den Kernen wurden oft homogene, eosinophile Einschlußkörper beobachtet (YosmoKa 1958, KLöNE 1958).

Inzwischen liegen zahlreiche Berichte über die Isolierung des Masernvirus in Zellkulturen vor (verschiedene Nährmedien, methodische Verbesserungen, Fluorescenz-cytologische Untersuchungen usw.). BLAck u. Mitarb. (1956) züchteten das Masernvirus in Kulturen aus menschlichen Spinaliomzellen, dies gelang auch DEKKING und MoCARTHy (1956). In Zellkulturen aus menschlichem Amnionepithel, menschlichen Nieren und Affennieren isolierten das Masernvirus Enders (1956), Enders u. Mitarb. (1957), Ruchle (1957), Mrlovanovic u. Mitarb. (1957), BeCH (1958), FrankeL und KING-WEST (1958), in menschlichen Herzzellkulturen Grrardr u. Mitarb. (1958), und schließlich konnten KaTz u. Mitarb. (1958) einen an das Hühnerbrutei adaptierten Stamm des Masernvirus in Kulturen von Hühnerembryo-Geweben zur Vermehrung bringen. HsidNG u. Mitarb. (1958) zeigten, daß das Masernvirus in Monolayer-Kulturen von Nierenzellen einer afrikanischen Affenart (Erythrocebus patas) feine, aber deutliche Plaques mit scharfen Rändern bildet (mit Hilfe der Plaque-Technik sind quantitative Bestimmungen und Neutralisationstests mit Masernvirus durchführbar). Weitere Einzelheiten über die Züchtung des Masernvirus, über seine Eigenschaften und Beziehungen zu anderen Virusarten s. bei KLöne (1958), bei SHERMaN und RUCKLE (1958), bei Enders u. Mitarb. (1959), bei McCarthy (1959) und bei RaPP (1960).

Die Isolierung des Masernvirus gelingt aus dem Blut und aus dem Rachenspülwasser (am besten vor Ausbruch des Exanthems oder innerhalb der ersten 48 Stunden nachher). Die bisher isolierten Masernstämme verhielten sich antigenetisch einheitlich. Im Blutserum der Rekonvaleszenten können neutralisierende und komplementbindende Antikörper nachgewiesen werden. Die ersten Antikörper finden sich schon bald nach Ausbruch des Exanthems, ihren Gipfeltiter erreichen sie etwa 4 Wochen später. Dann vollzieht sich ein langsamer Abfall der Titer bis zu einer Minimalhöhe, die lebenslänglich bestehen bleibt (andauernde Immunität). Der Neutralisationstest wird am besten in Gewebekulturen durchgeführt. Antigene für die Komplementbindungsreaktion können aus Eikulturen oder Zellkulturen hergestellt werden. 
Das Masernvirus hat eine Größe von 120 bis $140 \mathrm{~m} \mu$. Ultrahistologische Untersuchungen der Hautveränderungen beim Masernexanthem liegen bisher noch nicht vor.

\section{e) Therapie und Prophylaxe}

Ein spezifisch-wirkendes Mittel gegen Masern gibt es noch nicht. Der Wert der Antibiotica und Sulfonamide für die Beherrschung der bakteriellen Sekundärinfektionen wurde schon erwähnt. Symptomatica (Zink-Augentropfen, Antipyretica, Acedicon oder Codein, Mundpflege usw.) verstehen sich von selbst.

Die passive Immunisierung mit Rekonvaleszentenserum oder Gammaglobulinen (letzteres am besten!) bei Masern hat sich bewährt, und zwar viel besser als intramuskulär gegebenes Erwachsenenblut oder -serum. Der erzielte Schutz ist abhängig von der Dosishöhe und vom Zeitpunkt der Injektion. Gammaglobulin (z. B. das der Behringwerke) wird mit $0,2 \mathrm{~cm}^{3}$ bis $0,4 \mathrm{~cm}^{3}$ pro kg Körpergewicht dosiert. Wird in dieser Menge Gammaglobulin innerhalb der ersten 3 Tage nach der Exposition (bzw. Infektion) zugeführt, so ist fast stets ein völliger Schutz vor der Erkrankung zu erwarten, der etwa 2 bis 3 Wochen andauert. Wird das Gammaglobulin später (bis zum 4. oder 5. Tag der Inkubation) appliziert, so verlaufen die Masern mitigiert (SPIESs 1958).

Antibiotica- und Gammaglobulinbehandlung beeinflussen die Masernencephalitis nicht (hierüber und über die passive Masernimmunisierung allgemein $\mathrm{s}$. bei Häckel 1952, Mrrovsky und Seidler 1955 sowie bei Allen und Frank 1956).

Gegenwärtig wird intensiv an der aktiven Immunisierung gegen Masern gearbeitet (erste Versuchsserien laufen, Resultate stehen noch aus). Eine Virulenzabschwächung des Masernvirus gelang nach Anpassung eines auf Zellkulturen isolierten Stammes an embryonales Hühnergewebe. Damit war die Voraussetzung für die Herstellung einer, ,Lebend-Vaccine " geschaffen (ENDERS-RUCKLE 1960).

\section{Scharlach}

\section{a) Definition}

Der Scharlach (Scarlatina) ist eine akute Infektionskrankheit hierfür Prädisponierter. Der Kontagionsindex beträgt $35 \%$, ist jedoch örtlichen und zeitlichen Schwankungen unterworfen. Die Eintrittspforte für das infektiöse Agens und die Lokalisation des Primäraffektes bildet nach SchukrmanN (1958), ,in den meisten und typischen Fällen der Nasen-Rachenraum". Die initialen Krankheitserscheinungen bestehen aus einer Angina (,nahezu obligat"), einem Enanthem (düsterroter Rachen, streifiges Erythem des Gaumens, ,Himbeerzunge"), einem charakteristischen Exanthem sowie aus regelmäßiger Temperatursteigerung. Einem erscheinungsfreien Intervall folgt bei einem Teil der Fälle ein sogenanntes ,Zweites Kranksein" (Scharlachnephritis, Herzbeteiligung, Otitis, Typhoid, Scharlachrheumatoid), evtl. mit Wiederholung des Exanthems (STRöDER 1956).

Die Frage, ob der Scharlach nur eine Streptokokkeninfektion darstellt oder zusätzlich ein Virus als Erreger in Betracht kommt, ist noch immer nicht absolut sicher geklärt. „Im Vordergrund steht nach wie vor die Streptokokkenätiologie“ (STRöDER 1956). Die pathogenetische Beteiligung von hämolysierenden Streptokokken der Gruppe A (bei $97 \%$ der Scharlachpatienten) steht eindeutig fest. BINGEL (1947 a, b, c, 1949) vertritt die Ansicht, daß die hämolysierenden Streptokokken entweder ,"pyogen" oder ,,scarlatinogen" wirken und daß dieses unterschiedliche Verhalten durch An- oder Abwesenheit eines „Begleitvirus“ bedingt wird. Demnach soll nur die „Streptokokken-Virus-Kombination" die Scharlach- 
noxe erzeugen (Virus an die Streptokokken parasitär oder symbiontisch gebunden). Bereits HEGLER (1946) glaubte, daß ein Virus ,Schrittmacher für die Streptokokken" sein könnte. Die Begleitvirus-Hypothese ist nicht ohne Widerspruch geblieben (z. B. seitens des Arbeitskreises um KIKUTH und GRÜN). Entschieden ist die Streitfrage noch nicht. Auffällig bleibt, daß der Scharlach in den letzten Jahren (allgemeiner Einfluß der Antibiotica, Genius epidemicus?) fast ausschließlich milde Verlaufsformen zeigt (von zahlreichen Autoren wird wiederholt betont, daß gegenwärtig die Häufigkeit der bakteriellen Infektionen ab- und die der Viruskrankheiten zunimmt) und daß es trotz der modernen Zellkulturen-Technik noch nicht gelungen ist, das "Scharlach-Virus" zu isolieren. Utber den zurZeit leichten Scharlachverlauf s. bei RoMINGER (1955) und ZISchinsky (1957).

\section{b) Differentialdiagnose}

Am häufigsten muß der Scharlach gegen Masern (s. S. 365), gegen scarlatiniforme Arzneimittelexantheme, gegen das Grippe-Scarlatinoid (s. bei „Influenza“" S. 345 und bei STröder 1956), gegen Rubeolen (s. S. 370) und gegen den Scharlachähnlichen Rash bei Varicellen (Klärung durch Verlauf) abgegrenzt werden.

Differentialdiagnostisch wichtige Symptome und Hilfsmittel: Auslöschphänomen von Schultz-Charlton, Dick-Test (Injektion von $0,1 \mathrm{~cm}^{3}$ Toxin intracutan: Rötung und Schwellung [d.h. positive Dick-Reaktion] nur bei Nichtimmunen), Dermographie blanche, Hautfollikelschwellung, Himbeerzunge, beträchtliche Leukocytose und spätere ,Scharlachschuppung“. Die Inkubationszeit des Scharlachs ist nicht streng normiert. Sie beträgt meist 2 bis 5 Tage (Grenzen: 1 bis 24 Tage).

Bei Scharlacherkrankung können in den Leukocyten die von DöHLE beschriebenen rundlich-ovalen Einschlußkörper beobachtet werden. Sie besitzen einen gewissen differentialdiagnostischen Wert, sind aber sicher nicht „Virus-Kolonien“ (experimentelle Erzeugung beim 'Tier durch Diphtherietoxin möglich).

Die Hauthistologie ist kaum für die Differentialdiagnose des Scharlachs zu verwerten. Die wesentlichste Veränderung der Scharlachhaut ist die sehr starke Erweiterung und Füllung der Capillaren im Papillarkörper und im unteren Corium (,maximale Gefäßparalyse" nach UNNA). Die Epidermisveränderungen sind weitgehend von der Stärke der entzündlichen Exsudation im Papillarkörper abhängig (histologische Details bei GaNs und STEIGLEDER 1957).

Erwähnt sei noch, daß kürzlich RADL und HkKELE (1959) über ein 10jähriges Mädchen berichteten, bei dem im 5. Lebensjahr eine Psoriasis mit einem pustulösen Schub auftrat. Im 10. Lebensjahr kam es drei Tage nach Beginn einer Scharlacherkrankung erneut zur Ausbildung einer Psoriasis pustulosa vom Typ Zumbusch.

\section{c) Therapie und Prophylaxe}

Allgemein wird die Auffassung geteilt, daß der Penicillinbehandlung des Scharlachs ein bedeutender Wert zukommt. Nach Dost (1957) wird heute angenommen, daß eine Penicillintherapie nur dann sinnvoll ist, wenn sorgfältige Ausschaltung jeder Reinfektionsmöglichkeit gewährleistet ist; (andernfalls müssen Komplikationen die Folge sein, die als "Hospitalisierungsschäden" bezeichnet wurden). Außer Zweifel aber steht der günstige Einfluß des Penicillins auf die initialen Krankheitserscheinungen (Angina, Temperaturen).

Bei schweren, hypertoxischen Scharlachfällen ist auch heute noch die Therapie mit Scharlachserum indiziert. Die Prophylaxe mit Scharlachserum (passive Immunisierung) hat sich hingegen nicht bewährt. 
Nach WiEsener (1958) besteht über die Eignung des Scharlachimpfstoffes zur aktiven Immunisierung keine einheitliche Meinung. Mit Adsorbatimpfstoffen muß mindestens zweimal im Abstand von 4 Wochen eine Injektion von $1 \mathrm{~cm}^{3}$ (1. Injektion) bzw. $0,5 \mathrm{~cm}^{3}$ (2. und evtl. 3. Injektion) erfolgen, um einen relativen Impfschutz von etwa zweijähriger Dauer zu erzielen. Bessere Wirkung ist nach dreimaliger Impfung zu erwarten. Zur Scharlachimpfung führt WIESENER (1958) aus: ,Zu Epidemiezeiten hat auch eine Scharlachschutzimpfung prophylaktischen Wert. Eine generelle Anwendung kann bei den zur Zeit milde verlaufenden Erkrankungen und der anhaltend guten Wirksamkeit von Penicillin nicht empfohlen werden. Bei der üblichen Dreifachimpfung verdient neben Diphtherie- und Keuchhustenimpfstoff der gut verträgliche und wirksame Tetanusimpfstoff den Vorzug vor der Scharlachimpfstoffkomponente."

\section{Rubeola}

a) Synonyma

Röteln, Rubella, German Measles, Epidemic Roseola, Three-day-measles, Rubéole.

\section{b) Definition}

Röteln stellen eine akute Viruskrankheit dar, die vorwiegend Kinder befällt und gekennzeichnet ist durch ein rosarotes, grob- oder kleinfleckiges, generalisiertes Exanthem, durch Lymphknotenschwellungen und ein sog. ,,buntes Blutbild". In den ersten 2 bis 3 Schwangerschaftsmonaten kann eine Rubeoleninfektion schwere Fruchtschäden verursachen. Röteln sind weltweit verbreitet (sporadisches Auftreten, kleinere, selten größere Epidemien). Der Kontagionsindex ist geringer als bei Masern. Die Krankheit ist 2 Tage vor bis 5 Tage nach Auftreten des Exanthems ansteckend. Die Inkubationszeit beträgt 14-18 (23) Tage. Die Übertragung geschieht in Form der Tröpfcheninfektion. Am häufigsten erkranken Kinder zwischen dem zweiten und zehnten Lebensjahr, aber auch ältere Kinder und jugendliche Erwachsene (Erkrankungen jenseits des 30. Lebensjahres sind selten). Röteln hinterlassen langdauernde Immunität, Zweiterkrankungen kommen selten vor. Erwachsene können evtl. einen schwereren Verlauf durchmachen als Kinder, die z.T. die Krankheit überstehen, ohne bettlägerig zu werden. Das Exanthem heilt gewöhnlich nach 2 bis 3 Tagen ab, zuweilen besteht Juckreiz. Es gibt Fälle von Röteln ohne Exanthem (Rubeola sine exanthemate, dann nur Schwellung der Lymphknoten, ein buntes Blutbild und evtl. Fieber). Die Prognose der Röteln ist überwiegend gut. Eine ernste Komplikation ist die seltene Röteln-Encephalomyelitis (WInter 1954, DahL 1955, CANTwell 1957 und RILEY 1958).

\section{c) Differentialdiagnose}

Röteln müssen abgegrenzt werden von Masern (evtl. bei gleichzeitiger Masernund Rötelnepidemie sehr schwierig, Cukndet 1948), Scharlach, Lues (Serologie), Ringelröteln und von rubeoliformen Exanthemen bei Mononucleosis infectiosa und ECHO-Virusinfektionen (s. dort). Von Masern unterscheiden sich die Röteln vor allem durch Fehlen der Koplikschen Flecke (Enanthem bei Röteln: kleine rote Flecken am weichen Gaumen) und durch die Plasmazellenvermehrung im peripheren Blut ( 5 bis $12 \%$, ja bis zu $34 \%$ Plasmazellen). Beim Scharlach kommt es meist vom 5. bis 6 . Tag an zur Entwicklung einer Eosinophilie, im Gegensatz zu Rubeolen keine Schwellung der occipitalen, cervicalen und retroauriculären Lymphknoten. 
Maretić u. Mitarb. (1958) fanden bei einem Fall von Röteln, bei dem einer Appendicitis wegen laparotomiert werden mußte, ein ausgedehntes, diffuses Enanthem des Peritonaeums.

Die Hauthistologie bei Rubeolen ist für die Differentialdiagnose nicht von Bedeutung (Epidermis : geringe Acanthose, Corium: mäßig starker entzündlicher Prozeß im Bereich des oberen Blutgefäßnetzes, Infiltrate aus Histio-, Lympho- und Leukocyten um Follikel und Schweißdrüsen und perivasculär). Die Veränderungen sind durchweg weniger stark ausgeprägt als bei Masern. Über die histologischen und cytologischen Details s. bei LIPSCHÜTZ (1932).

Die katarrhalischen Veränderungen (Rhinitis, Pharyngitis, Bronchitis und Conjunctivitis) sind bei Röteln im allgemeinen viel flüchtiger als bei Masern. Sie können wie das Fieber gänzlich fehlen.

\section{d) Laboratoriumsdiagnose}

Das Rötelnvirus kann über das Respirationssystem von Mensch zu Mensch übertragen werden (infektiöses Material: Ultrafiltrat von Nasensekret; Versuche von ANDERson 1949). Derselbe Autor berichtete 1954 über die Isolierung des Virus in Zellkulturen aus Affennierenepithel. Erst in der 5. Passage traten cytopathische Veränderungen auf: herdförmig angeordnete multinucleäre Zellen und große mononucleäre Zellen. Dieser cytopathogene Effekt ließ sich durch Zugabe von Rekonvaleszentenserum verhindern. Das in der Gewebekultur angereicherte Agens konnte nicht auf Affen übertragen werden. Das Resultat ANDERsons ist bisher durch andere Untersucher noch nicht reproduziert worden.

Gelungene Übertragungen vom Menschen auf mehrere Affenspecies sind mehrfach in der Literatur mitgeteilt worden. Die Berichte über erzielte Vermehrung des Rötelnvirus in Eikulturen sind nicht überzeugend, ebenfalls nicht die elektronenoptischen Darstellungen des infektiösen Agens durch REaGaN u. Mitarb. (1953). Siehe hierüber: NAUCK (1958) und ENDERS-RUCKLE (1960).

SeEBerg (1951) beobachtete bei Tuberkulin- (Mantoux-Reaktion) und Diphtherietoxin-Injektionen (Schick-Reaktion) bei Rötelnkranken schwache oder negative Ausfälle der Hautreaktionen solange das Exanthem bestand, stärkere Reaktionen nach Abblassen des Ausschlages. Analoge Ergebnisse erhielt SEEBERG bei Scharlach- und Masernpatienten (,unspezifische Anergie der Haut").

Eine für die Routineuntersuchung im Laboratorium geeignete Nachweismethode des Rötelnvirus ist noch nicht bekannt.

\section{e) Therapie und Prophylaxe}

Antibiotica beeinflussen die Rubeoleninfektion nicht. Experimentelle Grundlagen für eine aktive Rubeolenschutzimpfung sind vorhanden, doch ist die praktische Durchführung zur Zeit noch nicht möglich (Shaughnessy 1957, SpIess 1958).

Für die passive Immunisierung ist die Applikation von Gammaglobulin geeignet $\left(0,2-0,4 \mathrm{~cm}^{3}\right.$ pro $\mathrm{kg}$ Körpergewicht, WARD und PARKer 1956 , KRUGMaN und WARD 1958). Die Injektion des Gammaglobulins muß innerhalb der ersten drei Tage nach der Infektion erfolgen. Die Schutzwirkung ist nicht unbedingt sicher, bei weitem nicht in dem Maße wie gegenüber Masern. Am besten geeignet ist Gammaglobulin aus Rötelnrekonvaleszentenserum. Die Schutzdauer beträgt etwa 2-3 Wochen. Unbedingt indiziert ist die Zufuhr von Gammaglobulinen bei Graviden, bei denen die Möglichkeit einer Infektion innerhalb der ersten vier Schwangerschaftsmonate gegeben war. Die Injektion sollte möglichst bald nach der Exposition durchgeführt werden (SPIEss 1958). 
Gravide Frauen sollten in der ersten Hälfte der Schwangerschaft unbedingt von Rötelnkranken ferngehalten werden. Von manchen Autoren wird vorgeschlagen, Mädchen vor der Pubertät künstlich mit Röteln zu infizieren, d. h. ihren Kontakt mit einem an Rubeolen erkrankten Kind zu fördern (,,Kindergesellschaften bei Rötelnpatienten "), um einer späteren Rubeoleninfektion während der Schwangerschaft vorzubeugen (BLANK und RAKE 1955, NaUCK 1958).

\section{f) Embryopathia rubeolosa}

Von GregG (1942) wurde zuerst darauf hingewiesen, daß bei Kindern, deren Mütter im ersten Trimenon der Schwangerschaft an Rubeolen erkrankt waren, Schädigungen folgender Art auftreten konnten: Katarakt, Mikrophthalmie, Herzmißbildung, Mikrocephalie, Taubheit, Zahnanomalien und psychische Defekte.

Unterschieden werden muß zwischen Gameto-, Embryo- und Fetopathien. Die Ursache der Gametopathien sind Veränderungen der männlichen und weiblichen Keimzellen vor der Konzeption (z. B. Mongolismus). Die Fetopathien hemmen die Reifung der Frucht oder lassen diese in den letzten zwei Dritteln der Schwangerschaft absterben (z. B. Lues, Toxoplasmose, Cytomegalie). Embryopathien hingegen führen im ersten Drittel der Gravidität zu krankhaften Veränderungen der Frucht (z. B. Röteln). Nur die Gameto- und Embryopathien, nicht die Fetopathien, verursachen Fehlbildungen. Letztere sind phasenspezifisch und faktorenunspezifisch, d.h. es ist gleichgültig, ob der Faktor das Pocken- oder Rötelnvirus ist, wichtig ist nur der Zeitpunkt des Einwirkens, d. h. der Infektionstermin innerhalb der ersten drei Schwangerschaftsmonate. Dies verdeutlicht die Tabelle 37 (aus der Monographie von Flamm 1959).

Mit dem Problem der Embryopathien

Tabelle 37. Termin der Virusinfektionen innerhalb der ersten 3 Schwangerschaftsmonate und Art der verursachten Miß. bildungen (nach Framm 1959)

\begin{tabular}{|c|c|}
\hline $\begin{array}{l}\text { Virusinfektionen } \\
\text { während der } \\
\text { Graviditätswochen }\end{array}$ & $\begin{array}{l}\text { Mißbildungen des } \\
\text { Embryo }\end{array}$ \\
\hline 5 & Katarakt \\
\hline $5-7$ & Herzfehler \\
\hline $5-7$ und $9-12$ & Innenohrschäden \\
\hline $8-9$ & Milchzahndefekte \\
\hline
\end{tabular}
durch das Rötelnvirus beschäftigen sich Arbeiten von WERTHEMaNN (1948), SWAN (1949), Müller und SchäfGer (1950), SELaNDER (1950), WOLFF (1950), GÜNTHER (1952), TöndURY (1952), KAYE u. Mitarb. (1953), Germer (1955), LÜTZENKIRCHEN (1955), Budolfsen (1956), Frokwis und Plattwer (1956), Неснт (1956), Коерpe (1956), Morari (1956), Doerr (1957), Greenberg u. Mitarb. (1957), LoRANT (1957), GERMER (1958), Hull u. Mitarb. (1958) sowie von KARTE (1958) u. a. (weitere Literatur, pathologisch-anatomische, klinische und virologische Einzelheiten s. bei Flamm 1959).

Neuere Untersuchungen über die Rubeolenembryopathie ergaben, daß mit 10 bis $15 \%$ Mißbildungen gerechnet werden muß, wenn die Mutter in den ersten drei Monaten der Schwangerschaft an Röteln erkrankt (GERMEr 1960). Eine gesetzliche Regelung über die Vornahme einer Schwangerschaftsunterbrechung im Falle einer Rötelninfektion im ersten 'Trimenon liegt bis jetzt noch nicht vor. Es muß individuell von Fall zu Fall entschieden werden (z. B. Übernahme des Risikos seitens einer älteren Erstgebärenden).

\section{Rubeola scarlatinosa}

\section{a) Synonyma}

Vierte Krankheit (nach Masern, Scharlach und Röteln), Fourth Disease. 


\section{b) Definition}

Wahrscheinlich kommt dieser Infektionskrankheit keine selbständige Stellung zu. Möglicherweise ist das Krankheitsbild der Rubeola scarlatinosa entweder eine besondere Verlaufsform der Röteln oder eine ,sehr leichte Variante“ des Scharlachs (sehr kleinfleckiges Exanthem). Hegler (1946) brachte die Beziehungen des Exanthems der „Vierten Krankheit" zu den klassischen Exanthemen auf folgende Formel: „Röteln verhalten sich zu Masern wie die Vierte Krankheit zu Scharlach".

Die Inkubationszeit soll 9 bis 20 Tage betragen. Beobachtungen über eine spezifische Immunität liegen nicht vor. Bereits Monawetz (1930) schrieb: „Für die Selbständigkeit dieser Krankheitsform würde nur ein epidemisches Auftreten sprechen, ohne daß dabei Übertragungen von ausgesprochenem Scharlach oder Röteln stattfinden." - Bisher wurde kein Virus isoliert, das als spezifischer Erreger der Vierten Krankheit in Betracht kommt. Möglicherweise sind früher durch ECHO-Viren ausgelöste Exantheme als „Rubeola scarlatinosa“ angesprochen worden, vielleicht auch Gripps-scarlatinoide.

\section{Erythema infectiosum acutum}

\section{a) Synonyma}

Ringelröteln, Kinderrotlauf, Fünfte Krankheit, Megalerythema epidemicum (oder ,infectiosum"), Fifth Disease, Cinquième maladie, Quinta malattia, Mégalerythème épidémique, Erythema contagiosum, Erythema simplex marginatum, Erythema infectiosum morbilliforme, Exanthema variabile. - Weitere Synonyma bei Korting (1951). Bei letzterem und bei Korntner (1959) s. auch die Geschichte dieser Krankheit.

\section{b) Definition}

Beim Erythema infectiosum handelt es sich um eine akute Infektionskrankheit, deren Erreger mit großer Wahrscheinlichkeit ein Virus ist. Gekennzeichnet ist die Krankheit durch eine Polymorphie des Exanthems, durch das häufige Fehlen von Allgemeinsymptomen, durch die z. T. lange Bestandsdauer der Hauterscheinungen und durch die Bevorzugung des weiblichen Geschlechtes. Es erkranken besonders häufig Mädchen im Alter von 6 bis 15 Jahren.

\section{c) Klinik}

Die Inkubationszeit beträgt 7 bis $14(6-17)$ Tage. Am häufigsten werden Kinder im Alter von 6 bis 15 Jahren (unter einem Jahr kommen selten Erkrankungen vor), aber auch Jugendliche, selten ältere Erwachsene befallen (Mädchen und jüngere Frauen werden bevorzugt).

Prodromalerscheinungen fehlen oft. Vor Ausbruch des Exanthems können sich gelegentlich Müdigkeit, Appetitlosigkeit, Durchfall, Kopf- und Leibschmerzen, Kältegefühl, katarrhalische Symptome, Lichtscheu, Halsschmerzen, subfebrile Temperaturen, evtl. auch mäßig starke, nicht druckempfindliche Schwellungen der Lymphknoten und Gelenkschmerzen einstellen. Im allgemeinen verläuft die Krankheit aber sehr leicht und ohne Fieber.

Das Erythema infectiosum ist keine sehr häufige Krankheit, es tritt in größeren Zeitabständen in Form kleinerer Epidemien auf (z. B. 1942 in Kuba: Exposito 1956 oder in der Umgebung von Detroit 1956-1957: Condon 1959). Pandemien sind sehr selten (größere Epidemien z. B. 1913/14 in Breslau mit über 1000 Fällen, 1951/52 in Frankreich; weitere epidemiologische Daten s. bei TRüв und PoscH 1959). Gern tritt das Erythema infectiosum im Frühjahr und Herbst auf. Die 
Übertragung geschieht durch direkten Kontakt (wahrscheinlich durch Tröpfcheninfektion). Die Krankheit ist weit verbreitet (Europa, Amerika, Asien, s. Details bei Kortivg 1951).

Das Exanthem tritt plötzlich auf. Zunächst bilden sich kleine, leicht erhabene (,urticarielle“), stecknadelkopf- bis linsengroße, rote Flecken im Bereich von Wangen und Stirn. Unter Aussparung von Oberlippe, Nasolabialfalte und Kinn kann durch Konfluenz der Efflorescenzen eine Schmetterlingsfigur entstehen, deren Farbe zuerst hochrot ist und auf Druck schwindet, die später eine livide Note erhält und deren Ränder leicht erhaben sind (Aussehen wie Erysipel). Die Haut fühlt sich heiß an und ist prall gespannt. Die großen Wangenherde blassen im weiteren Verlauf zuerst im Zentrum ab. Etwa 1 bis 3 Tage nach Befall des Gesichtes dehnt sich der Ausschlag auf die Streckseiten der Arme und Beine, gelegentlich auch auf den Rumpf und die Beugeseiten der Extremitäten aus (Springen des Exanthems). In der Regel bleiben Handteller, Hand- und Fußrücken, Fußsohlen und die Kopfhaut frei.

Auch bei den nicht im Gesicht befindlichen Läsionen handelt es sich um große, scharf begrenzte, intensiv-rote, erhabene, z. T. quaddelförmige Flecken mit späterer Tendenz zum Konfluieren. Es bilden sich dann große girlandenförmige Plaques oder landkartenähnliche Figuren (,Ringelröteln“, „Megalerythem“). Nicht immer ist der cyanotische Farbton im weiteren Verlauf sehr ausgeprägt. Das Exanthem bleibt meist 4 bis 7, auch 10 Tage bestehen (selten bis zu 24 Tage). Es kann Juckreiz vorhanden sein. Von manchen Autoren wird der Pruritus als „lebhaft", „heftig" oder ,lästig" angegeben. Gelegentlich jucken die Hauterscheinungen nicht.

Die Abheilung des Exanthems kann mit und ohne Schuppung (,Schälung“) erfolgen. Zu stärkerer Schuppung kommt es vor allem bei ausgeprägter exsudativer Komponente der Hautveränderungen. Hinterlassen von Pigmentierungen ist selten (z. B. leicht-bräunlich pigmentierte Flecken, die nach einigen Wochen von selbst verschwinden), häufiger hingegen behält die Haut an den Partien, die vom Exanthem ergriffen wurden, noch längere Zeit ein marmoriertes Aussehen. Nachkrankheiten wie beim Scharlach gibt es nicht.

Enantheme (kurz vor oder beim Auftreten des Exanthems) sind häufig zu beobachten, und zwar kommt es vorwiegend zur Entwicklung kleiner roter Flecken auf der Wangenschleimhaut und am Gaumen, z. T. auch zur Bildung punktförmiger Petechien (GLanzmann 1952).

Das Exanthem des Erythema infectiosum besitzt gern einen Wechsel in der Farbintensität (z. B.: lebhaft rote Farbe im Liegen, beim Stehen Umschlag von rot in eine livide Färbung, WaLther 1949). Durch mechanische Reizung der Haut kann das Exanthem an schon abgeheilten Partien zum Wiederauftreten gebracht werden (passager!). Dieser Eigenschaft und der Polymorphie des Exanthems wegen hat PosPISchILL (1904) das Erythema infectiosum „Exanthema variabile" genannt.

Das Adjektiv ,,variabile“ verdient die Krankheit in mehr als einer Hinsicht. Möвus (1954), der ein guter Kenner des Erythema infectiosum ist, betonte, daß 84 Fälle, die er vor allem im ersten Halbjahr 1953 selbst beobachten konnte, den Definitionen in den Lehrbüchern meist nicht entsprachen. Häufig fehlten die Schmetterlingsfiguren im Gesicht, das gesamte Exanthem blieb kleinfleckig und heilte nach wenigen Tagen ohne Neigung zur Konfluenz und ohne Residuen ab. Die Fälle von Möвus zeigten keinen Unterschied in der Geschlechtsverteilung, keine jahreszeitliche Häufung, von den 84 Kranken waren 6 Säuglinge und Prodrome waren nicht selten. Von MöBUs wird besonders hervorgehoben, daß Intensität und Dauer des Wangenerythems sehr wechseln können und „,daß es 
oft nur als blühendes Aussehen imponiert, ferner, daß es die einzige Manifestation des Erythema infectiosum bleiben kann".

Der Stamm soll beim Erythema infectiosum selten befallen werden. Dies wird allerdings von manchen Autoren bezweifelt und Möвus führt hierzu aus: „COERPER schildert ausgeprägte Fälle treffend als ,,mit Exanthem förmlich übergossen." Man mag einwenden, daß dieser Befund anscheinend nicht bei allen Epidemien gleich häufig und markant in Erscheinung trat; aber bei der verblüffenden Regelmäßigkeit, mit der wir ihn vor allem bei jüngeren Kindern beobachten konnten, halten wir es doch für angezeigt, wenn er in Zukunft allgemeinere Erwähnung findet." MöBus meint, daß gelegentlich ,fast jede Körperstelle" Hautveränderungen aufweisen kann; (im Hinblick auf die primäre und sekundäre Virämie in der Pathogenese der exanthematischen Virusinfektionen wäre dies nur natürlich).

In Anlehnung an die Verlaufsformen, die PosPischill (1904) herausgestellt hat, hat Möвus den Exanthemverlauf des Erythema infectiosum folgendermaßen gegliedert:

1. Stadium: „Schmetterlingsförmige Gesichtsröte", mit ihr zugleich oder kurz darauf tritt das

2. Stadium auf, das Morbilloid. Es handelt sich um ausgedehnte kleinfleckige, z. T. urticariell erhabene Efflorescenzen, mit Unterschieden in der Intensität und Ausbreitung. Beim voll ausgeprägten, typischen Krankheitsbild folgt nach kürzerer oder längerer Zeit das

3. Stadium, das sog. „Erythema gyratum“. Die Girlandenbildung bevorzugt deutlich die Streckseiten der Extremitäten.

Die 84 Patienten, die MöBus (1954) untersuchte, verteilen sich unter Zugrundelegung dieses Schemas folgendermaßen:

1. Nur Gesichtsröte: 4 Fälle.

2. Deutliche Gesichtsröte und Morbilloid: 9 Fälle.

3. Typische Ringelröteln (mit Girlanden): 35 Fälle.

4. Verdacht auf Erythema infectiosum (Abortivformen): 36 Fälle (!).

Wenn zwei Stadien einwandfrei nachzuweisen sind, kann nicht mehr von abortiver Erkrankung gesprochen werden. Die Prognose des Erythema infectiosum ist stets gut.

Mehrfach sind Exanthemverläufe mit stärkerer exsudativer Komponente (Abgrenzung gegen Urticaria, z. T. lokalisierte Ödeme im Bereich der Unterarme, Ohrmuscheln und Augenlider) angegeben worden. Im Hinblick auf die zahlreichen Formen und Varianten des Exanthems sprach Pospischill von einem ,reizvollen Wechsel des schönsten und kunstvollsten aller Exantheme."

Die Exanthemdauer schlüsselte sich bei MöBus wie folgt auf:

$$
\begin{aligned}
& \text { 1-2 Tage . . . . } 10 \text { Patienten } \\
& \text { 3-5 Tage . . . . . . 25 Patienten } \\
& \text { 6-10 Tage . . . . . . } 19 \text { Patienten } \\
& \text { 11-15 Tage . . . . . } 11 \text { Patienten } \\
& \text { Mehr als } 15 \text { Tage . . . . } 2 \text { Patienten } \\
& \text { Nicht genau zu ermitteln . . } 17 \text { Patienten }
\end{aligned}
$$

Ausgeprägte Schuppung sah MöBus nur in einem Falle.

Kurzdauernde Temperatursteigerungen sind nicht ungewöhnlich. Enantheme sah Möвus selten. Kopliksche Flecken treten beim Erythema infectiosum nie auf. Lymphdrüsenschwellungen verschiedener Stärke und Lokalisation (gern submandibulär) kommen im Exanthemstadium häufiger vor. Die Diazo-Reaktion des Harnes ist negativ. 
Die Krankheit hinterläßt eine langdauernde Immunität. Rezidive sind selten. Über seltene Komplikationen s. bei KoRNTNER (1959) ${ }^{1}$.

Höhere Temperaturen beim Erythema infectiosum beobachteten BoulaRD und Pierre (1953).

Die Blutkörperchensenkungsgeschwindigkeit ist beim Erythema infectiosum entweder nicht oder nur gering beschleunigt (GREITHER 1958).

Das Blutbild ist nicht sehr charakteristisch. Meist findet sich eine Leukopenie mit relativer Lymphocytose ( $80-90 \%$ Lymphocyten). Später kann sich eine Eosinophilie (bis über $10 \%$ ) entwickeln. Plasmazellen - wie bei Rubeolen werden nicht beobachtet.

Die Histologie der Hauterscheinungen weist keine typischen Veränderungen auf (KoRTing 1951, Werner 1958, Korntner 1959). Die oberen Epidermislagen sind unverändert. Im unteren Stratum spinosum entstehen örtlich begrenzte Quellungen. Es finden sich spongiotische Herde, die z. T. zur Ausbildung kleiner Bläschen führen. In die spongiotischèn Bezirke können Rundzellen einwandern. Auffällig kann die Häufung der Mitosen sein. Überwiegend im Stratum papillare des Coriums, aber auch in den tieferen Cutisschichten bilden sich Hyperämie und Ödem aus. Meist ist das Gefäßendothel nicht sichtbar geschädigt, doch kommen Endothelschwellungen vor. Entzündliche Infiltrate (lympho-histiocytär) sind sowohl perivasculär als auch um die Haarfollikel und die Schweißdrüsen, nicht aber um die Talgdrüsen angeordnet (GREITHER 1958).

\section{d) Differentialdiagnose}

Von Röteln unterscheidet sich das Erythema infectiosum durch die längere Bestandsdauer des Exanthems, durch die viel geringeren Lymphknotenschwellungen und durch das Blutbild (keine Plasmazellen!).

Von Masern grenzt sich das Erythema infectiosum durch die nicht oder nur unterschwellig vorhandenen katarrhalischen Erscheinungen, durch das Fehlen der Koplikschen Flecken und des Fiebers sowie durch die andere Verteilung und Erscheinungszeit des Ausschlages ab.

Scharlach gegenüber ist eine Abtrennung durch das Auslöschphänomen, das Blutbild, das Fehlen einer ausgeprägten Pharyngitis sowie einer Angina und durch die Farbe des Ausschlages (bei Scharlach keine cyanotische Tönung) möglich.

Die Differenzierung gegenüber einem Erysipel stützt sich auf das gute Allgemeinbefinden beim Erythema infectiosum (meist kein Fieber, kein Schüttelfrost) und auf das Fehlen von Efflorescenzen an anderen Körperpartien (z. B. beim Gesichtserysipel).

Vom Erythema exsudativum multiforme läßt sich das Erythema infectiosum durch den andersartigen Gesichtsbefall, durch das Fehlen eigentlicher „Kokarden" und durch das meist vorhandene Freibleiben von Hand- und Fußrücken sowie Handtellern und Fußsohlen unterscheiden, vom Erythema anulare centrifugum Darier ebenfalls durch die Besonderheit des Gesichtsbefalles und durch die andere Entwicklungsart des Exanthems.

Die Trennung von der akuten Urticaria (Infektiosität, Anamnese, Verteilung der Efflorescenzen) ist meist leicht durchzuführen, ebenfalls eine solche gegenüber Arzneimittelexanthemen. Ähnlichkeit mit dem Erythema infectiosum soll zuweilen das Kalomelexanthem bei Kindern nach Genuß von Wurmschokolade haben.

1 Bisher wurden beim Erythema infectiosum 3 Todesfälle beobachtet, doch fielen sie sämtlich nicht dem Erythema infectiosum zur Last, sondern anderen Faktoren. 
Vom Exanthema subitum (Roseola infantum) läßt sich das Erythema infectiosum durch den meist fieberfreien Verlauf und das länger-dauernde Exanthem abgrenzen; (an Exanthema subitum erkranken außerdem fast nur Säuglinge).

Das Bostoner Exanthem trägt gewisse Wesenszüge des Erythema infectiosum, ist aber wohl nicht mit diesem identisch. Es wird durch Enteroviren verursacht, (s. im Abschnitt ,ECHO-Viren“ S. 360).

\section{e) Therapie}

Eine besondere Therapie kommt bei dem meist leichten Verlauf des Erythema infectiosum nicht in Betracht. Die Linderung des Juckreizes kann durch blande Schüttelmixturen (Tumenollotio, Scheroson F-Lotio) und durch Antihistaminica (Sandosten-Calcium, Synpen) erreicht werden.

\section{f) Ätiologie}

Allgemein wird eine Virusätiologie des Erythema infectiosum angenommen. Eine Züchtung des infektiösen Agens auf der Chorionallantoismembran von Bruteiern oder eine Übertragung auf die üblichen Laboratoriumstiere gelang bisher nicht.

Anläßlich einer Erythema infectiosum-Epidemie in Reading (Pennsylvanien) konnten WERNER u. Mitarb. (1957, 1958) ein Virus in Gewebekulturen aus Affennierenepithel isolieren (cytopathogener Effekt in fortlaufenden Passagen). In den infizierten Zellen entwickelten sich zum Teil intranucleäre Einschlußkörper. Besonders charakteristisch aber war die Bildung sehr großer syncytialer, polynucleärer Riesenzellen in den beimpften Kulturen. Ein cytopathogener Effekt, wenn auch von geringerem Ausma 3 , trat auch in infizierten Zellkulturen aus menschlichem Amnionepithel auf. Elektronenoptische Untersuchungen mit dem isolierten Virus stellten Partikel mit einem Durchmesser von etwa 100 mu dar. Neutralisationsversuche in Zellkulturen wiesen engere serologische Beziehungen zwischen Masern und Erythema infectiosum nach. Wegen der Ähnlichkeit der Antigene von Masern- und Erythema infectiosum-Virus und weil beide Viren große, vielkernige Riesenzellen bilden und etwa die gleiche Größenausdehnung besitzen, meint WERNER (1958), daß das Erythema infectiosum-Virus in dieselbe Erregergruppe wie das Masernvirus gehöre, diesem also nahestehen müsse. Diese Resultate des Wernerschen Arbeitskreises sind bisher von anderer Seite noch nicht bestätigt worden.

\section{g) Exanthema infectiosum variabile-Epidemie 1958}

In Kiel wurden in den letzten Julitagen 1958 die ersten Patienten mit einem Exanthem beobachtet, das klinisch sowohl mit dem Erythema exsudativum multiforme - (diese differentialdiagnostische Erwägung ist fast so alt, wie das Erythema infectiosum als Krankheitsbild bekannt ist) - als auch mit dem Erythema infectiosum Ähnlichkeiten aufwies, dessen Symptomatologie aber doch in mehreren Punkten von den üblichen Bildern dieser beiden Krankheiten abwich. Hegler (1946) hat besonders die Beziehungen der Polymorphie des Erythema infectiosum zum morphologischen Bild des Erythema exsudativum multiforme hervorgehoben. Bei keiner Epidemie dürfte aber die exsudative Komponente im Exanthem des Erythema infectiosum so beträchtlich - (und daher auch die Ähnlichkeit mit dem multiformen Erythem so groß) — gewesen sein wie bei derjenigen des Jahres 1958. Da diese besonderen Krankheitsfälle in Kiel und Umgebung in der Folgezeit immer häufiger auftraten, gab ScHIRRFN sen. im August 1958 einen ersten Situationsbericht. Die Epidemie breitete sich dann 
rasch vom Norden der Bundesrepublik nach Westen, Süden und nach WestBerlin aus. Dem Schirrenschen Hinweis folgten bald entsprechende Beobachtungen aus anderen Städten, u. a. aus Hamburg (SoHrRREN sen. und RoHDE 1958, KImmig, Rohde und Hagenow 1959), aus dem Bezirk Osnabrück-Münster (Kolloquium über die Erythema infectiosum-Epidemie in Westfalen am 12. XI. 1958, veranstaltet von P. JoRdAN), aus Düsseldorf (Schreus 1958), aus Wuppertal (Haknsch und Blatch 1959), aus Mainz (Theisen 1958), aus Frankfurt a. M. (Gans 1959), aus West-Berlin (Spier 1959, Grimmer 1959, Ariexander 1959, Teller und Krüger 1959), aus Kronach (Ofr.) von KunzFeld (1959) und aus München (Marchionini und Nasemann 1958, Monk und NasemanN 1959 sowie Nasemann, StetTwieser und Röckl 1959). Ausführliche epidemiestatistische Erhebungen über die Erythema infectiosum-Pandemie 1958 im Land NordrheinWestfalen publizierten TRÜB, Posch und Laforet (1959).

In der Münchener Klinik wurde der erste Fall des infektiösen Exanthems am 31. X. 1958 gesehen. Am nächsten Tag folgten vier Patienten, in den daran anschließenden zwei Wochen täglich bis zu etwa 20 Exanthemfälle. Dann nahm die Frequenz ab und nach Ablauf eines Monats wurden keine Neuerkrankungen mehr beobachtet. Genaue Daten über die Gesamtzahl der Erythema infectiosumErkrankungen in der Bundesrepublik liegen nicht vor. Für West-Berlin nimmt man 40 bis 50000 Erythema infectiosum-Fälle an (Schätzung). Nach TRÜB u. Mitarb. (1959 a, b) erkrankten in den Bundesländern Hessen und Niedersachsen $1-1,5 \%$ der Bevölkerung. Dabei bestand eine Prävalenz der Altersjahrgänge über 14 Jahre (minimal: 69\%; maximal: 73\%; hingegen Jahrgänge von 0 bis 14 Jahre: minimal $28 \%$; maximal $31 \%$ ). Das weibliche Geschlecht wurde im Verhältnis ,,3 bis 4 zu 1 " häufiger als das männliche befallen ( $\delta$ : minimal $23 \%$; maximal $30 \%$; 오: minimal $71 \%$, maximal $75 \%$ ). Einzelheiten s. bei Trüв u. Mitarb. (1959 a, b). Im Volksmund hieß die Erkrankung ,,Bläschen-

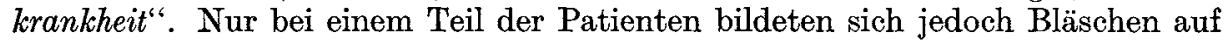
der Haut aus.

Das klinische Bild zeichneten Nasemane, StetTwieser und RöckL wie folgt auf: „Nach unterschiedlich häufig vorhandenen Prodromi von wenigen Tagen Dauer begannen die Hauterscheinungen in der Regel ziemlich plötzlich mit kleinen, etwa stecknadelkopfgroßen, hell- mitunter dunkelroten Flecken, die bald Linsengröße erreichten und dann nicht selten eine ausgesprochen urticarielle Note erhielten. Oft vergrößerten sich die Flecken schon im Verlaufe weniger Stunden erheblich, z. B. auf Markstückgröße, konfluierten teilweise und führten mitunter bis zur Eruption von typischen Quaddeln, z. T. mit anämischem Hof. Bei sehr stark ausgeprägten Hautveränderungen und Neigung der Efflorescenzen zur Konfluenz bestanden am Kulminationspunkt urticarielle, polycyclische Platten bis zur Ausdehnung einer Handfäche, insbesondere im Bereich der Ober- und Unterarme, der Oberschenkel sowie des Gesichtes (Wangenpartien). Einzelne konfluierte Herde zeigten einen intensiv roten, urticariellen Randsaum sowie leicht eingesunkene und angedeutet livide Zentren. In einigen Fällen war die exsudative Komponente so stark, daß es entweder zu massiven ödematösen Schwellungen (z. B. beider Arme) nach Art des Quinckeschen Ödems oder aber zur Bildung von Bläschen bzw. walnußgroßen Blasen vor allem an den Armen und im Gesicht kam. Bei einigen Patienten traten neben roten Flecken mit und ohne urticarieller Note, ausgesprochenen Quaddeln, Bläschen und Blasen auch Petechien auf. So gut wie immer gingen die Hauterscheinungen mit stärkerem Juckreiz einher, der mitunter kurze Zeit vor der Manifestation des Exanthems einsetzte."

Aus dieser Beschreibung geht hervor, daß das Krankheitsbild seinem Charakter nach kein „Erythem“ ist. An der Infektiosität der Krankheit schienen keine 
Zweifel zu bestehen. In Anlehnung an den von Pospischill (1904) geprägten Terminus hat Gass (1959) besonders in Ansehung dieser beiden Tatsachen die Bezeichnung ,Exanthema infectiosum variabile“ gewählt, die nur in Richtung auf die Infektiosität präjudiziert, den historischen Tatsachen jedoch Rechnung trägt, die Beziehungen zum Erythema infectiosum andeutet und auch noch zutreffen würde, wenn die ätiologische Forschung den Beweis beibringen könnte, daß völlige Identität mit dem Erythema infectiosum vorliegt. Denn: Eine Formvariante des klassischen Erythema infectiosum anzunehmen, hatte klinisch viel für sich. Hier soll also dem Gansschen Vorschlage gefolgt und von einem Exanthema infectiosum variabile gesprochen werden.

Die von anderen Autoren benutzten Namen, z. B. epidemische Hautfleckenkrankheit oder Großfleckenkrankheit für die klassischen Ringelröteln und Kleinfleckenkrankheit für die morbilliformen und rubeoliformen Fälle von Exanthema infectiosum variabile, sind z.T. recht unglücklich gewählt (die Polymorphie des Exanthema infectiosum variabile kommt nicht zum Ausdruck). Die von SPIER (1959) gewählten Begriffe sind hingegen entweder analog (,,polymorphes infektiöses Exanthem") oder treffen doch das Wesen des Exanthema infectiosum variabile (,Erythema infectiosum der Erwachsenen"). НAENSCH und BLAICH (1959) meinen im Hinblick auf die beobachteten großen Plaquebildungen, daß die Bezeichnung „Megalerythem" für das Exanthema infectiosum variabile besonders gerechtfertigt erscheint.

Nasemand, StetTwieser und RöckL (1959) haben 100 in München beobachtete Exanthema infectiosum variabile-Fälle näher untersucht. Es zeigte sich, daß im Verlauf des Exanthems die Exsudationstendenz schon nach wenigen Tagen deutlich abnahm. Die Quaddeln bildeten sich unter Hinterlassung anfänglich noch livider, später immer blasser werdender Flecke zurück. Zu feiner bis groblamellöser Schuppenbildung kam es vor allem im AnschluB an Blasen und Bläschen, außerdem bevorzugt im Bereich der konfluierten Herde an den unteren Extremitäten.

Etwa gleichzeitig mit dem Exanthem (zuweilen etwas vorher) kam es zur Ausbildung eines Enanthems, das sich auf Wangenschleimhaut, weichen und harten Gaumen, gelegentlich auch auf Tonsillen, Zunge und Lippen (rüsselförmige Schwellung der Lippen, SPIER 1959) erstreckte. Bei mehreren Patienten kamen gleichzeitig aphthöse Veränderungen der Gingiva (s. Abb. 145) sowie weißliche, umschriebene, fibrinöse Beläge auf den Tonsillen und in deren Umgebung vor. Im Bereich des weichen und harten Gaumens war das Enanthem vorwiegend diffus, an Wangen- und Lippenschleimhaut mehr fleckförmig angeordnet. Hier und da fanden sich auch Petechien. Das Enanthem befiel folgende Schleimhautareale:

1. Bis linsengroße rote Maculae fanden sich am häufigsten am weichen Gaumen, an der Uvula, auf den Tonsillen und an der Wangenschleimhaut, weniger häufig an den Lippen, an der Gingiva, auf der Zunge und am harten Gaumen.

2. Petechien traten am häufigsten an der Wangenschleimhaut, weniger oft am harten und weichen Gaumen auf.

3. Zur Bläschenbildung kam es nur gelegentlich an Wangenschleimhaut und Lippen.

4. Ebenfalls nur vereinzelt konnten Aphthen an Gingiva, Wangen- und Lippenschleimhaut festgestellt werden.

GrIMMER (1959; s. auch GrIMmer und JosEPH 1959) fand bei den Berliner Exanthema infectiosum variabile-Fällen ebenfalls fast immer ein Enanthem.

Von den 100 in München untersuchten Fällen waren 88 weiblichen und 12 männlichen Geschlechts. Bei Frauen und Männern waren die Altersgruppen von 21 bis 30 Jahren am häufigsten vom Exanthema infectiosum variabile befallen. 
Es folgten dann die Altersgruppen von 11-20 Jahren bei Männern und von 31 bis 40 Jahren bei Frauen. Exanthema infectiosum variabile konnte in München weder bei Säuglingen und Kindern bis zu 3 Jahren noch bei älteren Männern beobachtet werden.

Als Prodromalerscheinungen konnten, meist 1 bis 3 Tage vor Exanthembeginn, Rhinitis, Bronchitis, Hals- und Kopfschmerzen, Herpes labialis, Durchfälle, reduziertes Allgemeinbefinden und Pruritus festgestellt werden. Die Ausbreitung des Exanthems erfolgte durchweg sehr schnell innerhalb von

Abb. 146.

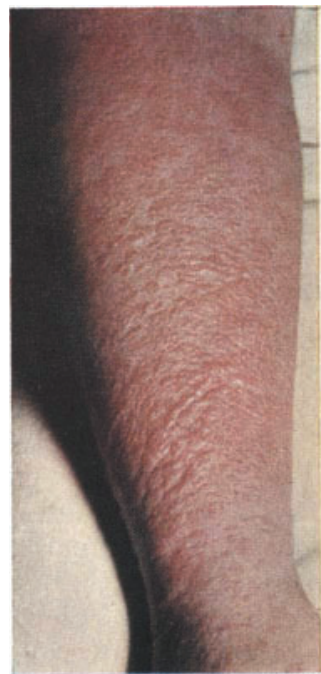

Abb. 145

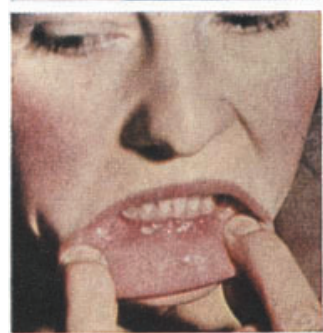

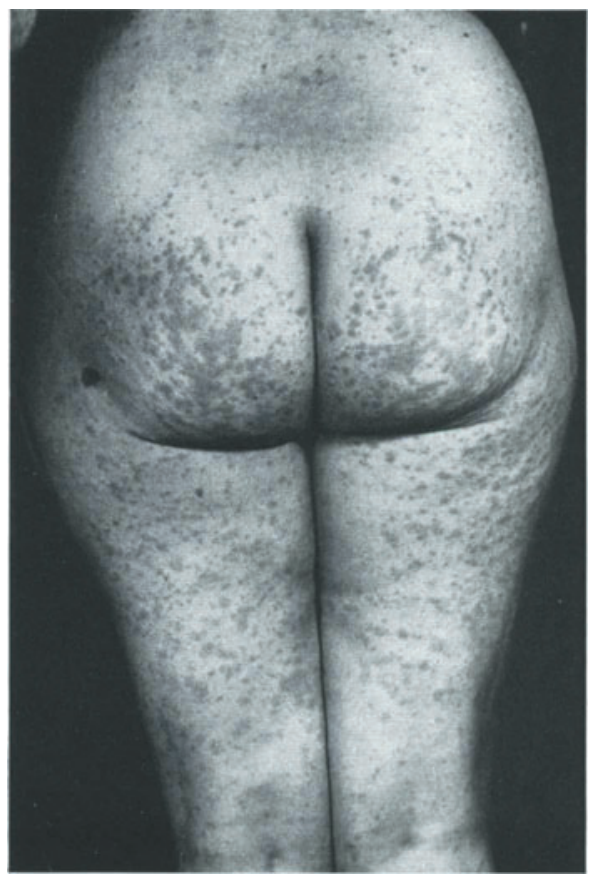

Abb.147

Abb. 145. Mundschleimhaut-Veränderungen bei Exanthema infectiosum variabile

Abb. 146. Exanthema infectiosum variabile, z.T. konfluierende „exsudative“ Efflorescenzen am Unterarm: Blasenbildung

Abb. 147. Exanthema infectiosum variabile. Erythematöse und urticarielle Efflorescenzen (Patientin H. A. 32 J.)

12-48 Stunden, seltener wurde hierfür bis zu 5 Tage benötigt. Der Pruritus war ganz überwiegend sehr stark ausgeprägt (85\%), mäßig bei $13 \%$ und nicht vorhanden nur bei $2 \%$ der Patienten.

Die Lokalisation wies gewisse Regelmäßigkeiten auf. Bevorzugt befallen wurden Arme, Handrücken, Oberschenkel und Gesicht. Von den 100 in München untersuchten Fällen ließ sich folgende Aufstellung über den Befall der verschiedenen Körpergegenden machen.

$$
\begin{aligned}
& \text { Gesicht ....... 62mal befallen } \\
& \text { Retroauriculargegend . . 56mal befallen } \\
& \text { Stamm (oft nur partiell) . . } 87 \mathrm{mal} \text { befallen } \\
& \text { Arme (Abb. 146) . . . . 100mal befallen } \\
& \text { Handrücken . . . . . } 77 \mathrm{mal} \text { befallen }
\end{aligned}
$$




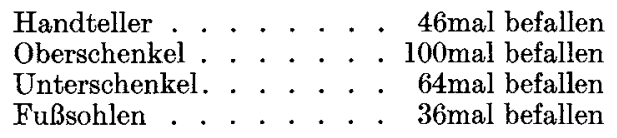

Grundsätzlich konnte jeder Körperteil von dem Exanthem befallen werden, auch Kopfhaut und Genitale (GRIMmer 1959). Die Aussaat der Efflorescenzen erfolgte z. T. unterschiedlich dicht. Die Abb. 147 zeigt z. B. bei einer Frau sehr dichtstehende Efflorescenzen des Exanthema infectiosum variabile im Bereich von Oberschenkeln und Gesäß, mehr isolierte, zerstreute Flecken und Quaddeln am Rücken und in den Kniekehlen. Bläschen- und Blasenbildung trat bevorzugt an den Streckseiten der Unterarme auf. Dieser stärkste Grad der Exsudation konnte von NASEMLAN, STETTwIESER und RöCKL (1959) bei insgesamt 6 von 100 Patienten beobachtet werden. Bläschen und Blasen, wie sie - wenn man vom Gesamtprozeß absieht - etwa dem Bilde einer akuten bullösen Dermatitis entsprechen würden, zeigt Abb. 146 (26jährige Patientin mit Exanthema infectiosum variabile), z. T. teigiges Ödem (SPIER 1959).

Die Bestanddauer des Exanthems war unterschiedlich lang und betrug meist 8 bis 20 Tage (Gipfel bei 12 bis 16 Tage; kürzeste Zeit: 3 Tage, längste Zeit: 28 Tage). Die Rückbildung der Hauterscheinungen setzte nach 3 bis 6 Tagen ein. Während des Exanthems kamen Störungen des Allgemeinbefindens nur bei etwa 10 bis $15 \%$ der Patienten vor (Müdigkeit, Schwindelgefühl, Halsschmerzen, Schüttelfrost). Febrile Temperaturen wiesen von den 100 Kranken nur 4 auf, davon bis $38^{\circ} \mathrm{C}$ : 2 Fälle und je ein Fall bis $39^{\circ}$ bzw. $40^{\circ} \mathrm{C}$. Über einen Todesfall berichtete HAHLWEG (1961).

Bei Kindern war der Gesamtverlauf etwas leichter, die Abheilung setzte rascher ein. Eine Patientin war 4 Wochen vor Ausbruch des Exanthems entbunden worden und stillte das Kind weiter ohne jede Unterbrechung. Der Säugling erkrankte nicht.

Im Sinne eines isomorphen Reizeffektes konnten an Druckstellen (z. B. Gürtelgegend) besonders zahlreiche, z. T. konfluierte Quaddeln und Flecke gesehen werden ${ }^{1}$. Nennenswerte Schwellungen der Lymphknoten traten nicht auf, Vergrößerungen der Leber und Milz kamen nicht vor. Serumeiweißlabilitätsteste und Harnuntersuchungen (Eiweiß, Zucker, Sediment, Urobilinogen) zeigten Werte im Bereich des Normalen. Die Blutkörperchensenkungsgeschwindigkeit (nach Westergreen) war entweder normal oder leicht beschleunigt. Die Serumeiweißelektrophorese ergab entweder keine Abweichungen von der Norm oder eine relative Gammaglobulinerhöhung auf 24-30,8 rel.- \%. HAENSCH und BLAICH (1959) beobachteten eine anfängliche Vermehrung der Alphaglobuline, später eine Gammaglobulinzunahme.

Bei der Untersuchung des Blutbildes wurden in den meisten Fällen normale bis gering erhöhte Gesamtleukocytenwerte gefunden, nur gelegentlich eine geringgradige Linksverschiebung. Bei einem Teil der Patienten bildete sich eine leichte Eosinophilie aus. Keine Vermehrung der Plasmazellen.

Die Therapie (Antihistaminica, Salicylate, blande Schüttelmixturen) hatte nur symptomatische Wirkung (Linderung des Juckreizes, Austrocknung der Bläschen).

Histologisch zeigt das Exanthema infectiosum variabile genau wie das Erythema infectiosum kein pathognomonisches Merkmal (Grimmer 1959, Teller und Krüger 1959, Enders-Ruckle, Heite und Siegert 1959, Trǘ und Posch

${ }^{1}$ Interessant ist die Beobachtung von SchIRREN sen. (persönliche Mitteilung), daß Besonnung das Exanthem verschlimmert. Dies ist auch bei anderen Viruskrankheiten wiederholt festgestellt worden. 
1960 u. a.). Neben zum Teil nur geringfügigen, mitunter etwas stärker ausgeprägten, perivasculären, aus Rundzellen, Histiocyten und Leukocyten bestehenden Infiltraten fand sich eine wechselnd starke ödematöse Durchtränkung des oberen Coriums (s. Abb. 148) und ein gleichfalls unterschiedlich starkes inter- und intracelluläres Ödem im unteren Teil des Stratum spinosum. Bei stärker ausgeprägter

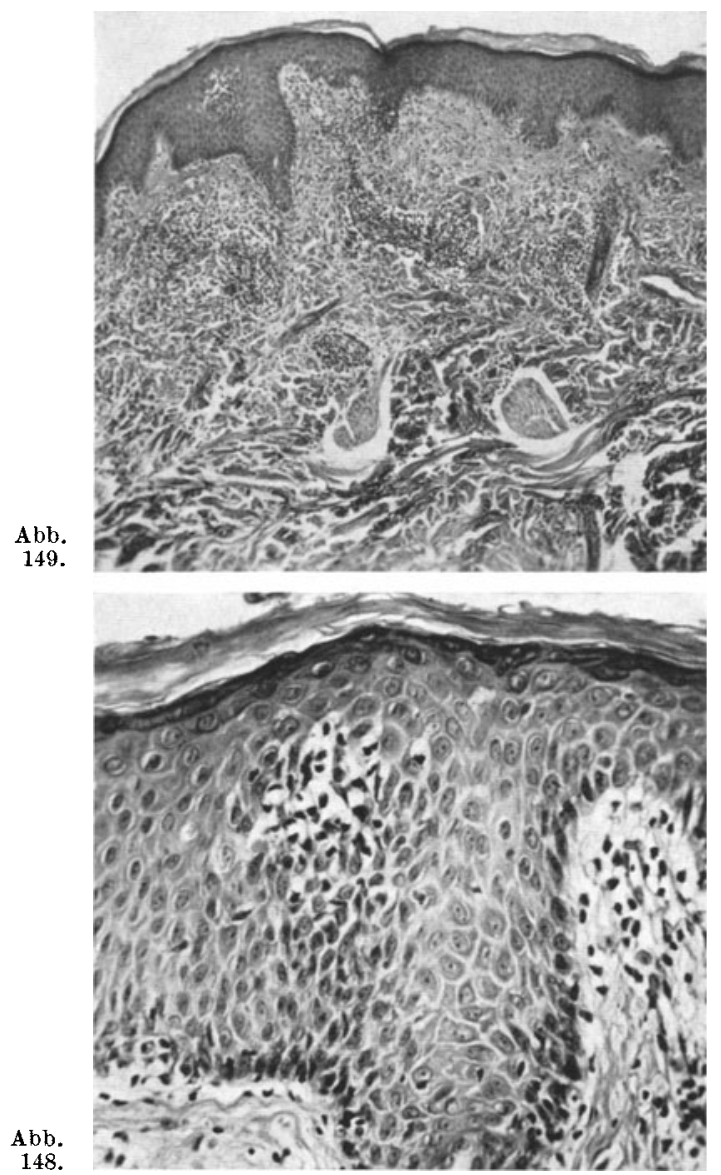

Abb. 148. Exanthema infectiosum variabile. Schnittpräparat: z.T. perivasculäre entzündliche Zellinfiltrate im Corium, Oddem, Hyperämie, leichte Spongiose im Stratum spinosum

Abb. 149. Wie Abb. 148, stärkere Vergr.: Spongiose im Stratum spinosum exsudativer Komponente konnte eine intraepidermale Bläschenbildung, wie wir sie ähnlich beim Ekzem finden können, beobachtet werden (Abb. 149).

Das Epithel zeigte vereinzelt Mitosen, nirgends aber intranucleäre oder zytoplasmatische Einschlußkörper. Im Corium, vor allem in den perivasculären Infiltraten, waren z.T. reichlich Eosinophile zu sehen. Der obere Gefäßplexus wies deutliche Hyperämie auf. Wie GrImMER (1959) betont hat, trat mitunter der petechiale Charakter der Veränderungen in Form von Blutungen ins Gewebe in den Vordergrund. Schwellungen des Gefäßendothels kamen vor, waren aber nicht regelmäßig zu finden. Manche Faserzüge von glatter Muskulatur waren homogen (nicht schollig) verquollen (GREITHER 1958).

Das von Ende Juli bis Anfang Dezember in Westdeutschland und West-Berlin beobachtete, epidemisch aufgetretene Exanthema infectiosum variabile hatte ohne Zweifel mit dem Erythema infectiosum acutum mehr Âhnlichkeit als mit allen anderen akuten infectiösen Exanthemen. Wie ENDERs-RuckLE, Heite und Siegert (1959) ausführten, sind die Meinungen der Autoren über die Wesensart des Exanthema infectiosum variabile in zwei Lager gespalten. Der Meinung der Autoren, die eine Identität von Ringelröteln und Exanthema infectiosum variabile bejahen (z. B. ScHREus 1958, Schreus und Heinisch 1959 und Grimmer 1959), steht die Ansicht jener gegenüber, die zunächst die Identität für nicht sicher halten und die Ergebnisse der ätiologischen Forschung abwarten wollen (z. B. Theisen 1958, Alexander $1959 \mathrm{a}, \mathrm{b}$ und GaNS 1959). Die Identitätsfrage ist letztlich nur ätiologisch klärbar (SPIER 1959).

Auch die Befürworter einer Identität von Erythema infectiosum und Exanthema infectiosum variabile betonen, daß zwischen der Epidemie von 1958 und früheren En- und Epidemien einige Unterschiede bestehen. Diese Abweichungen hat Schreus wie folgt zusammengestellt: 
1. Große geographische Ausdehnung. (Bemerkenswert war die schnelle Ausbreitung kurz vor dem Verebben).

2. Hohe Erkrankungsziffern. (Auch KorTing 1958 betont die hochgradige pandemische Durchseuchung und die hohe explosive Frequenz der Krankheit).

3. Bevorzugter Befall von Erwachsenen. (In erster Linie erkrankten junge Menschen zwischen 15 und 40 Jahren).

4. Mehr Erkrankungen bei Frauen als bei Männern und Kindern.

5. Juckreiz.

6. Vereinzelt hohes Fieber und Ödeme.

7. Blasen an den Extremitäten, teilweise zusammenfließend. (Die starke urticarielle Note wurde von allen Autoren hervorgehoben).

8. Exantheme auch an Palmae und Plantae. (Konting 1958 bezeichnet den Mitbefall von Handtellern und Fußsohlen als Novum).

9. Leukocyten von 7000 bis 22000 . (Keineswegs regelmäßig vorhanden!). 10. Eosinophilie zwischen 5 und 10\%. (Nicht immer!).

Die Abweichungen lassen sich noch ergänzen. Nach Korting (1958) waren der perakute Beginn, die Intensität und die Ausdehnung des Exanthems, das gelegentliche Auftreten von Hämorrhagien, die starke Rumpfbeteiligung, das Fehlen der sprunghaften Ausbreitung der Efflorescenzen und die Follikelmarkierung im Erythem (Cutis anserina roseoliformis) auffallend. Auch das ,MundKinn-Dreieck", das sonst beim Erythema infectiosum freibleibt, wurde beim Exanthema infectiosum variabile zuweilen mitergriffen (Alexander 1959). GaNs (1959) gab den Hinweis, daß bei einem Fall von Exanthema infectiosum variabile ein Erythema infectiosum in der Anamnese sicher ermittelt wurde. In der Vorgeschichte von Exanthema infectiosum variabile-Patienten fanden sich oft Angaben über durchgemachte Masern-, Röteln- und Scharlacherkrankungen. Bei Erythema infectiosum und auch bei Exanthema infectiosum variabile verläuft das Auslöschphänomen nach Schultz-CharLton sowohl mit Scharlachimmun- als auch mit Normalserum negativ (Gans 1959). Auch die Paul-Bunnelsche Reaktion fiel bei Exanthema infectiosum variabile-Patienten stets negativ aus (Alexander 1959). Pettenkofer und Niebuhr (1959) fanden beim Exanthema infectiosum variabile positive Kältehämagglutinationen und möchten dieses Resultat als Hinweis auf eine mögliche Virusätiologie der Krankheit deuten.

Trotz dieser Abweichungen vom ,klassischen“ Bild des Erythema infectiosum verfügt letzteres noch über viel Gemeinsames mit dem Exanthema infectiosum variabile: Polymorphie des Exanthems, leichter Verlauf, lange Dauer des Exanthems, die exsudative Komponente, die Bevorzugung des weiblichen Geschlechts, die mangelnde Spezifität der histologischen Veränderungen und den isomorphen Reizeffekt („Hervorlocken" des Exanthems durch mechanische Reizung). Möвus (1954) erwähnt, daß grundsätzlich jede Körperpartie beim Erythema infectiosum einmal vom Exanthem befallen werden kann. Die Beteiligung der Handteller und Fußsohlen sollte vielleicht nicht überbewertet werden. Säuglinge und Kleinkinder wurden zwar nur selten infiziert, doch liegen einige Beobachtungen hierüber vor (PAschkE 1959 u. a.). Die Eosinophilie gehört durchaus zum Bilde des Erythema infectiosum (wiederholte Hinweise in der einschlägigen Literatur; s. weiter oben!). Dasselbe gilt auch für den Pruritus. Bei einigen Epidemien wurde der Juckreiz zwar entweder nicht beobachtet oder in den Publikationen nicht erwähnt, doch gibt es zahlreiche andere Hinweise für die Zugehörigkeit dieses Symptoms zum Bild des Erythema infectiosum (MöBus 1954, Konntrer 1959). Ohne Zweifel kann der Pruritus von Fall zu Fall unterschiedlich heftig sein (wohl auch Unterschiede von Epidemie zu Epidemie). 
Die Frage, die zu entscheiden ist, lautet also: Ist das Exanthema infectiosum variabile eine Infektionskrankheit sui generis oder nur eine besondere Verlaufsform des Erythema infectiosum (Formvariante)? Es sollte nicht vergessen werden, daß das Erythema infectiosum auch als Exanthema variabile bezeichnet wurde und daß die Polymorphie der Krankheitsbilder immer im Vordergrund stand. Daß im Auftreten von Virusinfektionen durch Eigenschaftsänderungen des Erregers (aber auch der Wirte: Ernährungsfaktoren, allgemeine Hygiene, Cortisonmedikation, reichlicher Gebrauch von Antibiotica) - im Sinne des Genius epidemicus (z.B. durch mutative Vorgänge, die bei Viren durchaus möglich sind) Verlaufsunterschiede vorkommen können, ist lange bekannt. Das Exanthema infectiosum variabile als Formvariante des Erythema infectiosum anzusehen, die evtl. durch Mutation des Erregers bedingt wurde, ist keine abwegige Vorstellung. Doch sollten die Ansichten derjenigen Autoren nicht unbeachtet bleiben, die die Formenvarianz des Exanthema infectiosum variabile noch als Spielarten des ohnehin variablen Erythema infectiosum gedeutet wissen wollen.

Mit SpIER (1959) soll hier der Standpunkt vertreten werden, daß die Identitätsfrage nur über die Erforschung der Ätiologie entschieden werden kann. Eine andere Frage ist es, ob die Virusforschung nicht überfordert ist, wenn auf Anhieb von ihr die Lösung dieses Problems verlangt wird, $d . h$. die Isolierung und systematische Einordnung des Erregers ohne Ansehung der bisher noch spärlichen über das Erythema infectiosum-Virus bekanntgewordenen Daten.

Im Abschnitt (f) „Ätiologie des Erythema infectiosum" wurde dargelegt, daß die virologischen Kenntnisse über den Erreger des Erythema infectiosum noch sehr lückenhaft sind. Die Resultate des Wernerschen Arbeitskreises sind noch nicht bestätigt worden. Es ist demnach zwar wahrscheinlich, aber noch nicht absolut sicher, daß der Erreger des Erythema infectiosum eine dem Masernvirus nahestehende Virusart darstellt.

Die Vermutung, daß es sich bei dem Erreger des Exanthema infectiosum variabile auch um ein Virus handeln könne, lag nahe, da Erscheinungsbild und Verlauf denen anderer bekannter Virusexantheme ähnelten. Es war überraschend, daß von keinem Untersucher das Wernersche Virus nachgewiesen werden konnte.

Die Beobachtungen über die vermutliche Inkubationszeit des Exanthema infectiosum variabile stimmen mit denen des Erythema infectiosum in etwa überein ( 6 bis 10 Tage).

Erste mikrobiologische Untersuchungen mit Exanthema infectiosum variabile-Material führten SOHIRREN sen. und ROHDE (1958) durch (Züchtung des Herpes simplex-Virus aus Mundabstrichen), später isolierten KIMMIG, RoHDE und HAGENOW (1959) ein cytopathogenes Agens in Affennieren-Zellkulturen. RoHDE und LenNaRTz (1960) schlossen diese Versuchsserien (Isolierung eines Coxsackie $\mathrm{B}_{2}$ - und eines ECH0-11-Virusstammes) mit der Feststellung ab, daß die Ätiologie des Exanthema infectiosum variabile nicht geklärt werden konnte; die isolierten Agentien dürfen nicht als spezifische Erreger des Exanthema infectiosum variabile angesehen werden! Herzberg u. Mitarb. (1960) schließen sich auf Grund eigener Gewebekulturversuche dieser Meinung an.

In anderen Laboratorien wurden mehrere ECHO-Virustypen $(5,10,12$ und Subtyp 9) in Exanthema infectiosum variabile-Material aufgefunden (ENDERSRuckle, Heite und Siegert 1959, Enders-Ruckle 1959, Müller und Colli 1959). Über die ätiologischen Beziehungen des Exanthema infectiosum variabile zu den ECHO-Exanthemen s. den Abschnitt: ,ECHO-Virus-Isolierungen beim Exanthema infectiosum variabile" (B, III, 4, c). 
Munk (s. bei Munk und Nasemann 1959) konnte in Affennieren-Zellkulturen mehrfach ein cytopathogenes Agens isolieren, das sich in fortlaufenden Passagen weiterzüchten ließ (den cytopathischen Effekt s. in Abb. 150, die MunK uns freundlicherweise zur Verfügung stellte). Das isolierte Virus ließ sich nicht auf Babymäuse übertragen. Mit Seren verschiedener Exanthempatienten konnte das cytopathogene Agens in der Kultur einwandfrei neutralisiert werden, andererseits gelang es auch, von verschiedenen Patienten isolierte Viren mit dem Serum eines Kranken zu neutralisieren. Serologische Typenbestimmung ergab, daß die isolierten Viren alle dem ECHO-Virus vom Typ 4 entsprachen.

Weitere Untersuchungsergebnisse: Das infektiöse Material konnte nicht auf Kaninchen, weiße Mäuse und Bruteier übertragen werden und in HeLa-Zellkulturen keinen cytopathischen Effekt verursachen. Ausstrichpräparate von Bläschenflüssigkeit (Färbung nach HERZBERG, Paschen und nach Morosow) zeigten keine Strukturen, die als Viruselementarkörper hätten angesprochen werden können. Auch elektronenmikroskopisch konnten im Bläscheninhalt keine Elementarkörper festgestellt werden (NASEmanN, SteTtwieser und Röckl 1959).

Bei der elektronenoptischen Durchsicht von Dünnschnitten (Einbettung kleiner Exzisate aus Hautefflorescenzen in Methacrylat nach Fixation in $1 \%$ iger gepufferter Osmiumsäure, Herstellung der Schnitte mit dem Sjöstrandschen Ultramikrotom) sah Verf. in den Zellen des Stratum spinosum im Cytoplasma, meist in kleinsten Vacuolen gelegene, z. T. sehr zahlreiche feine Granula mit

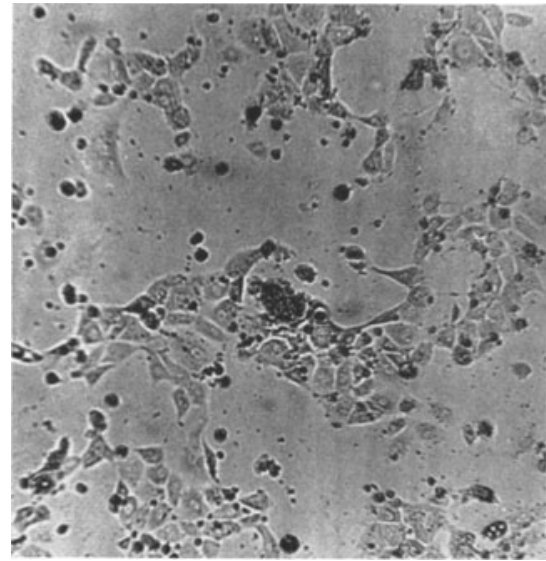

Abb. 150. Virusbeimpfte (infektiöses Agens aus Exanthema infectiosum variabile-Material: ECHOVirustyp 4) Affennierenzellkultur mit nicht vollstandigem cy topathogenem kffekt am 9. Tag, ungefärbte Zellen unter Nedium in der Kulturflasche aufgenommen. Vergr. etwa $60 \mathrm{mal}$. Aufnahme von K. MUNk, Munchen Durchmessern von etwa $30 \mathrm{~m} \mu$ (s. Abbildung 151). Die Zellkerne wiesen keine Einschlüsse auf. Cytoplasmatische Einschlußkörper wurden ebenfalls nicht beobachtet. Ob die im Plasma vorhandenen Granula Elementarkörper eines Virus sind, ist vorerst zweifelhaft. Auch in den Ultraschnitten war die Spongiose (weite Intercellularräume, siehe Abb. 151) deutlich zu sehen. In diesen Zwischenzellräumen konnten wir keine analogen kleinen Granula feststellen.

Seitens der Virologie geht es künftig um die Lösung folgender Fragen:

1. Ist das ,Wernersche Virus" der spezifische Erreger des Erythema infectiosum?

2. Ist das Exanthema infectiosum variabile wirklich infektiös und ist es eine Viruskrankheit?

3. Sind Erythema infectiosum und Exanthema infectiosum variabile identisch?

4. Besitzen ECHO-Viren ätiologische Bedeutung für eine oder beide Krankheiten?

Keine dieser Fragen konnte bisher endgültig beantwortet werden. Neue Aspekte wurden jedoch durch eine zweite Epidemie beigebracht, die 1960 in Holland auftrat. Durch epidemiologische Untersuchungen ließ sich nachweisen, daß die Erkrankungen zeitlich mit dem Absatz einer neuen Margarinesorte zusammenfielen, die einen besonderen Emulgator erhalten hatte. Die Verbreitung 
der Krankheit entsprach völlig dem Absatzgebiet dieser Margarine. Weiter konnte durch Nachforschungen beim Hersteller der Margarine ermittelt werden, daß dieselbe Margarinesorte auch in Deutschland verkauft worden war, und zwar nur zur Zeit der ,Exanthema variabile-Epidemie“" und in den ,Epidemiezonen“" (Westdeutschland und West-Berlin). In Holland nennt man daher das variable Exanthem ,Margarinekrankheit“. Ungeklärt ist noch der Entstehungsmodus.

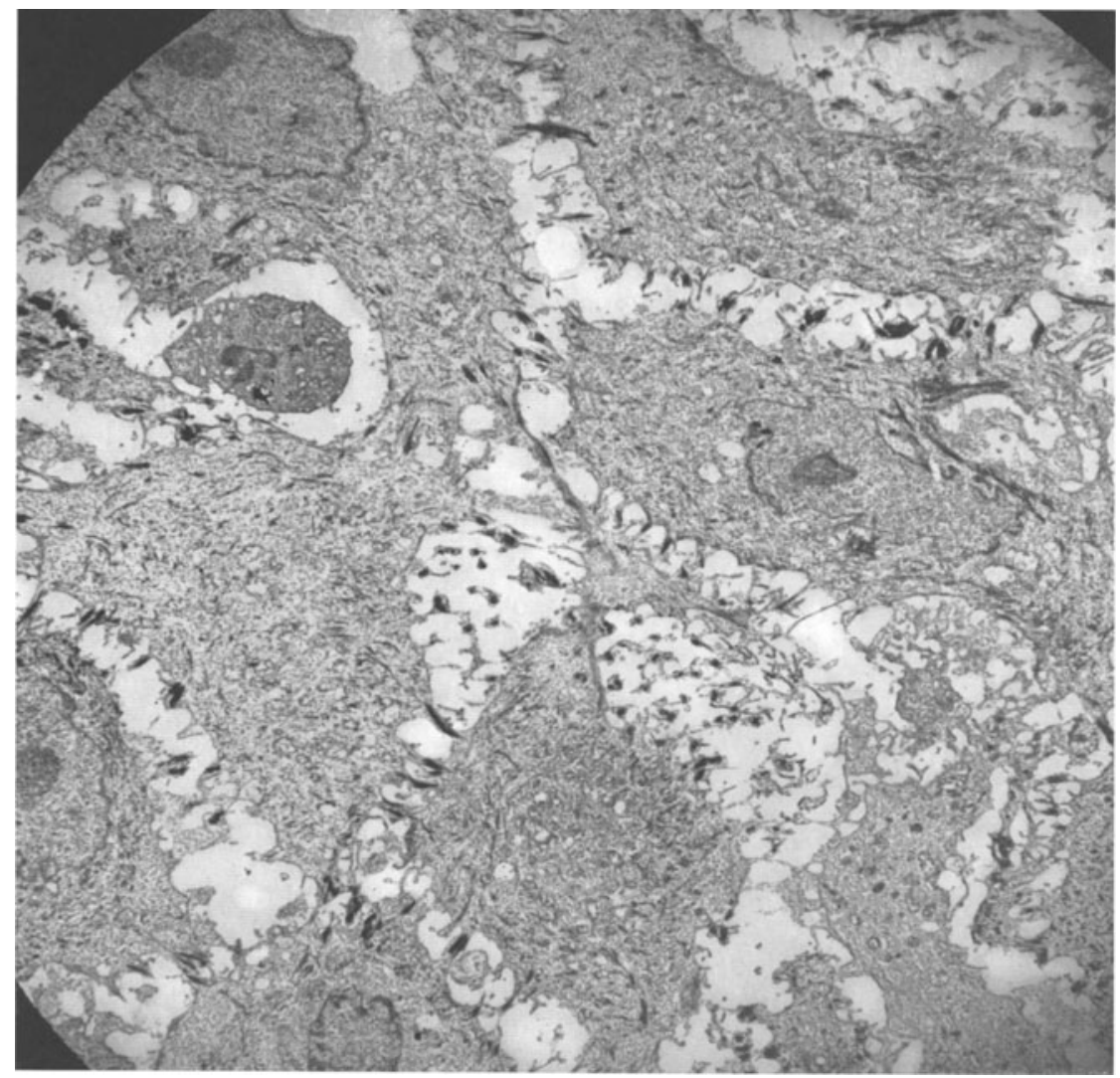

Abb. 151. Ultraschnitt aus Stratum spinosum (Exanthema infectiosum variabile). Weite Intercellularräume. Keine Einschlüsse in Zellkernen und im Cytoplasma. Feine Granula in kleinen Plasmavacuolen. El.opt. Aufnahme, Vergr. 4800 mal (OsO -fixiert) $^{-}$

Hermans (1961) wies darauf hin, daß auch in Holland bevorzugt junge Mädchen und Frauen erkrankten und daß keineswegs alle Personen befallen wurden, die die neue Margarine gegessen hatten, s. auch bei Huisman u. Mitarb. (1960). Auch freiwillige Versuchspersonen, die diese Margarine zu sich nahmen, erkrankten oft nicht. Patienten, die das Exanthem überstanden hatten, bekamen nach erneutem Margarine-Genuß gewöhnlich keinen neuen Exanthemschub. Die bisher durchgeführten Allergietests lieferten keine positiven Resultate (Hermans 1961). HAHLWEG (1961) meint — wohl etwas spekulativ —, daß die Virusätiologie des variablen Exanthems noch nicht widerlegt sei, da einerseits eine Verunreinigung der Margarine durch Viren möglich gewesen wäre, andererseits der der Margarine zugesetzte Emulgator die Voraussetzungen zur klinischen Manifestation einer Virusinfektion geschaffen haben könnte (Aktivierung latent vorhandener Viren). 


\section{Exanthema subitum}

\section{a) Synonyma}

Sechste Krankheit, Kritisches Dreitagefieber oder kritisches Dreitagefieberexanthem der kleinen Kinder, Roseola infantum sive subitum (auch R. infantilis), Exanthema criticum, Exanthema postfebrile, Pseudo-rubella, Three day fever, Rose rash of infants, Sixth disease, Zahorsky's disease, Duke's disease, La fièvre de trois jours des jeunes enfants, Sixième maladie, Esanthema subiania, Sesto malattia.

\section{b) Definition}

Ausführlich wurde diese Infektionskrankheit des Säuglings- und Kleinkindesalters zuerst von ZAHORSKY im Jahre 1910 beschrieben und „Roseola infantilis“" genannt. Von Glanzmann wurde die Bezeichnung ,Kritisches Dreitagefieberexanthem der kleinen Kinder" vorgeschlagen, die bereits eine Definition des Krankheitsbildes darstellt (über die Geschichte des Exanthema subitum s. bei KORNTNER 1959, dort auch Literatursammlung, und bei Möвus 1956).

Vom Exanthema subitum werden fast nur Kinder im Alter von 4 Monaten bis zu 21/2 Jahren (Höhepunkt der Anfälligkeit im zweiten Lebenshalbjahr) befallen. Auf diese Besonderheit wird von allen Autoren hingewiesen (Details bei WINDORFER 1954). Über die Infektabwehr bei Neugeborenen und die Anpassungsvorgänge nach der Geburt s. bei LinneweH und Stave (1960).

Die Krankheit kann in Epidemien und sporadisch auftreten. Zweiterkrankungen kommen möglicherweise vor $^{1}$ (Möвus 1959). Die Inkubationszeit wird mit 3 bis 7 Tagen (Grenzen 2-15 Tage) angegeben. Meist erkranken die Kinder plötzlich aus vollem Wohlbefinden heraus, ohne Prodromalerscheinungen. Da das Exanthema subitum für die Dermatologie keine große Bedeutung besitzt, sollen nur die Hauptsymptome genannt sein, und zwar in Anlehnung an MöBus (1959).

1. Akut einsetzendes hohes Fieber, meist Continua, dann kritischer Abfall nach 3 bis 4 Tagen.

2. Beim Fieberabfall (gelegentlich auch 1 bis 3 Tage später) schießt ein wechselnd stark ausgeprägtes, blaßrotes Exanthem auf (Rash-artig), das teils lediglich wenige Stunden, teils ein bis 2 Tage sichtbar bleibt und rubeoli-, morbilli- oder scarlatiniformen Charakter haben kann.

3. Meistens fehlen stärkere Allgemeinerscheinungen während der Fieberperiode (Rhinopharyngitis; Magen- und Darmerscheinungen kommen allerdings gelegentlich vor). Mit Auftreten des Exanthems fühlen sich die Kinder besser (kein neuer Temperaturanstieg!).

4. Zur Zeit des Fieberabfalles zeigt das Blutbild eine Leukopenie mit einer erheblichen relativen Lymphomonocytose.

5. Abheilung des Exanthems ohne Pigmentierung oder andere Residuen. Vorwiegend siedelt sich ersteres im Bereich des Stammes an. Schleimhautveränderungen wurden häufig beobachtet: Kleinfleckige Enantheme am Gaumen, deutliche Hyperämie im Rachen (auch ausgesprochene Pharyngitis), Rötung und Schwellung der Tonsillen (Glanzmann 1952).

Das Exanthema subitum kommt in allen Erdteilen vor, am häufigsten bisher in Nordamerika (dort werden etwa $30 \%$ aller Kinder befallen). Familiäre Kontaktfälle sind selten. Die Krankheit ist weniger kontagiös als Masern oder Varicellen. Möglicherweise muß mit gesunden, auch erwachsenen Virusüberträgern gerechnet werden.

${ }^{1}$ Die Frage, ob wirklich Rezidive vorkommen, ist schwer zu klären. Das flüchtige Exanthem kann von anderen Krankheiten imitiert werden (ECHO- und Grippe-Exantheme). 
Allgemein wird eine dauerhafte Immunität nach Exanthema subitum angenommen. Erst die Klärung der Ätiologie und die Ausarbeitung serologischer Nachweismethoden für die spezifischen Antikörper wird die Frage, ob es gelegentlich Zweiterkrankungen gibt, entscheiden. Verläufe ohne Exanthem sind mehrfach beschrieben worden.

Vogtherr (1957) meint, daß das Exanthema subitum in seiner Bedeutung oft unterschätzt würde. Es tritt sicher häufiger auf, als es diagnostiziert wird. Das liegt an den flüchtigen Hauterscheinungen und daran, daß letztere erst auftreten, wenn das Befinden des erkrankten Kindes wieder so gut ist, daß der Arzt nicht mehr benötigt wird.

Von manchen Autoren wird vermutet, daß das Exanthema subitum nicht so streng altersgebunden ist, wie bisher angenommen wurde. Bewiesen ist diese Vermutung allerdings noch nicht. Eine saisonale Häufung (Frühjahrs- und Herbstgipfel ?) ist nicht regelmäßig ausgeprägt.

Suboccipitale, cervicale und retroauriculare Lymphknoten sind häufiger angeschwollen. Neurologische Erscheinungen (Krämpfe, Meningismus) werden bei einem Teil der Kinder beobachtet. Gelegentlich gibt es schwere Verläufe mit Encephalitiden (BogDanowicz 1958, JosePH u. Mitarb. 1958 u. a.), doch ist die Prognose des Exanthema subitum überwiegend gut. Klinische Details s. u. a. bei Glanzmann (1952), Letchner (1956), Möbus (1956), Reis (1956), Kircher (1957) sowie bei Bogdanowicz und Szcepanska (1957). Eine besondere Therapie ist bei den meisten Fällen nicht notwendig.

\section{e) Differentialdiagnose}

Im Stadium febrile wird das Exanthema subitum am ehesten mit der Influenza verwechselt, im Stadium exanthematicum am häufigsten mit Masern. Bei dem voll-ausgeprägten Bild der Masern (Kopliks, typisches Exanthem, starke Prodromi, zweigipfeliger Temperaturverlauf, positive Diazoprobe) ist die Abgrenzung nicht schwierig. Bei Kleinkindern können die Masern jedoch atypisch verlaufen. Bei solchen Fällen vermögen oft epidemiologische Untersuchungen weiterzuhelfen.

Bei starker Konfluenz des kleinfleckigen Exanthems wird zuweilen Scharlach diagnostiziert. Hier entscheidet das Blutbild und die Tatsache, daß der Ausschlag beim Exanthema subitum erst am 4. Tag erscheint. Differentialdiagnostische Einzelheiten s. bei Windorfer (1954) und Möвus (1956).

Zur Abgrenzung von Röteln müssen Fieberverlauf, Blutbild, die viel stärkere Lymphknotenschwellung bei letzteren und die andere Altersdisposition (Rubeolen meist erst im Schulalter) herangezogen werden.

Rubeoliforme Exantheme werden auch bei der infektiösen Mononucleose gesehen. Sie lassen sich in der Regel leicht vom Exanthema subitum abtrennen (Lymphadenopathie, Milzvergrößerung, atypische lymphocytäre Zellen im Blutbild und positive Paul-Bunnel-Reaktion).

Differentialdiagnostische Schwierigkeiten können atypische Fälle von Erythema infectiosum und von Erythema exsudativum multiforme machen, (mitunter erst im weiteren Verlauf Klärung der Diagnose möglich). Auch Arzneimittelexantheme können vielfach nicht sicher ausgeschlossen werden. Möвus (1956) äußert hierzu: ,Wir können nur hoffen, daß Virusnachweis oder serologische Methoden uns hier bald weiterhelfen werden!"“

\section{d) Neuere ätiologische Untersuchungen}

KEMPE u. Mitarb. (1950) konnten das Exanthema subitum experimentell von Mensch zu Mensch übertragen (intravenöse Injektion des Blutserums eines 
erkrankten Kindes, 9 Tage später typisches Exanthema subitum). HELLsTRöM und VAHLQUist (1951) vermochten die Resultate von KEMPe u. Mitarb. (1950) $\mathrm{zu}$ bestätigen.

Auf die üblichen kleinen Laboratoriumstiere kann das Exanthema subitum nicht übertragen werden. Das infektiöse Agens dieser Krankheit läßt sich nicht auf der Chorionallantoismembran von Bruteiern zur Vermehrung bringen. KEMPE u. Mitarb. (1950) gelang es aber, Rhesusaffen (Macaca mulatta) zu infizieren, (die Tiere bekamen Fieber und Lymphknotenschwellungen, aber kein Exanthem). Näheres s. in der Übersicht von KorNTner (1959), vergl. auch die Affenversuche von Reaqan u. Mitarb. (1955). Die morphologische Darstellung des Erregers des Exanthema subitum durch die letztgenannten Autoren dürfte jedoch kaum beweisend sein; (im Elektronenmikroskop: Teilchen von sphärischer Form und mit Durchmessern von 100 bis $110 \mathrm{~m} \mu$ [?]).

ENDERS-RUCKLE (1960) isolierte kürzlich aus Rachenspülwasser und aus Stuhlproben von drei Kindern mit Exanthema subitum mit Hilfe von Zellkulturen cytopathogene Agentien, die dem ECHO-Virustyp 10 entsprachen. Die Autorin leitet jedoch vorerst keine ätiologisehen Folgerungen von diesem Ergebnis ab.

Fest steht, daß das Exanthema subitum eine infektiöse Erkrankung ist. Wahrscheinlich handelt es sich um eine Viruskrankheit, doch ist das Virus noch nicht sicher nachgewiesen. Es ist möglich, daß die Isolierung des Erregers in Zellkulturen schon bald einwandfrei gelingt. Dann wäre die mikromorphologische Darstellung seiner Elementarkörper (z. B. in Ultraschnitten befallener Zellen) ebenfalls ein lösbares Problem.

\section{Mononucleosis infectiosa}

\section{a) Synonyma}

Pfeiffersches Drüsenfieber, infektiöse Mononucleose, Monocyten-Angina, Glandular fever, angina with lymphatic reaction, acute benign lymphoblastosis, acute mononucleosis, benign lymphadenosis, mononucléose infectieuse.

\section{b) Definition}

Die akute Mononucleose ist eine Infektionskrankheit, von der vorwiegend Kinder und jugendliche Erwachsene befallen werden. Sie ist charakterisiert durch die Ausbildung einer Angina, durch Fieber, vergrößerte Lymphknoten, mitunter durch Milzschwellung und vor allem durch ein ausgeprägtes monocytäres Blutbild sowie durch das Auftreten heterophiler Antikörper im Blutserum (Paul-Bunnel-Reaktion). Die infektiöse Mononucleose wurde im Jahre 1889 zuerst von PFkifEER beschrieben. Sie ist sehr wahrscheinlich eine Viruskrankheit. Es kommen sporadische Erkrankungen vor, aber auch kleinere Epidemien (meist Kinder unter 10 Jahren), besonders in Kindergärten, Internaten, bei Soldaten, die in Kasernen zusammenleben, in Waisenhäusern und Schulen. Das Pfeiffersche Drüsenfieber wird selten bei Kindern unter 6 Monaten gesehen. Die Eintrittspforte des Erregers und die Art seiner Ausbreitung im Organismus ist bisher nicht bekannt.

Über die Geschichte, Klinik und Epidemiologie der infektiösen Mononucleose s. die Literaturzusammenstellung bei ANETSBERgER (1960).

\section{c) Haut- und Schleimhautbeteiligung bei der Mononucleosis infectiosa}

Bei der Mononucleosis infectiosa treten Haut- und Schleimhautveränderungen häufig auf. ANETSBERGER (1960) ermittelte aus einem Literaturgut von insgesamt 
1348 Fällen Hautsymptome bei 219 Patienten (= 16\%), und zwar: Exantheme 125mal $(=9 \%)$, Ikterus $67 \mathrm{mal}(=5 \%)$, Ödeme $57 \mathrm{mal}(=4 \%)$ und Hämorrhagien bei 40 Fällen $(=3 \%)$. Ulcera im Genitalbereich fanden sich nur bei 5 Fällen $(=0,3 \%)$. Schleimhautveränderungen waren bei 227 Fällen angegeben $(17 \%)$. Diese betrafen fast nur (204 Patienten) die Mundschleimhaut. Petechien wurden $108 \mathrm{mal}(=8 \%)$, Stomatitiden $4 \mathrm{Imal}(=3 \%)$, Gingivitiden $38 \mathrm{mal}(=2,9 \%)$ und kleinfleckige Enantheme $28 \mathrm{mal}(-2 \%$ ) beobachtet. Auch ödematöse Schwellungen im Bereich der Mund- und Rachenschleimhaut kommen vor ( $\sim 2 \%$ der Fälle). Abgesehen von den ulcerösen und ulceromembranösen Veränderungen der Tonsillen bilden sich geschwürige Prozesse im Cavum oris nur selten $(0,1 \%$ der ausgewerteten Fälle) aus. Ein- oder doppelseitige Conjunctivitiden fanden sich bei insgesamt 24 Kranken $(\sim 2 \%)$.

Die Exantheme bei der Mononucleosis infectiosa können morbilli-, rubeoli- oder scarlatiniformen Charakter annehmen, evtl. auch eine urticarielle Note aufweisen. Die Hautbeteiligung soll bei Epidemien häufiger sein (bis zu 70\%) als bei sporadischen Erkrankungen (GLanzmanN 1952). Nicht immer ist das Exanthem flüchtig, Rash-artig und nur zu Beginn der Krankheit zu beobachten. Gelegentlich besitzt es eine lange Bestandsdauer.

Ikterus oder Subikterus sind Folgen der fast immer vorhandenen Leberbeteiligung (Hepatitis, die klinisch oft nicht zu erkennen ist; Leberpunktate zeigen Wucherung der Kupfferschen Sternzellen, lymphocytäre Infiltrate im periportalen Raum, Einzelzellnekrosen; die Hepatitis mononucleosa kann histologisch von der Hepatitis epidemica unterschieden werden; Leberschwellung bei etwa $20 \%$ der Mononucleosis infectiosa-Kranken). Mitunter sind Ikterus und Exanthem gleichzeitig vorhanden.

Ödeme finden sich fast nur im Gesicht (z. B. Lidödeme zu Beginn der Krankheit als „Frühsymptom“). Generalisierte Petechien der Haut sind nicht sehr häufig. Das gilt ebenfalls für die Ekchymosen. Recht oft bilden sich dagegen Petechien in der Mundschleimhaut aus, am häufigsten im Bereich des weichen, seltener des harten Gaumens oder in der Wangen- und Zungenschleimhaut. Diese Schleimhautpetechien sind scharf begrenzt, messen etwa $1-2 \mathrm{~mm}$ im Diameter und sitzen auf reizlosem Grund. Oft sind 25 bis 100 und mehr Petechien vorhanden. Sie erscheinen etwa 2 bis 6 Tage nach Auftreten der Angina.

Die Stomatitiden können der Stomatitis aphthosa sehr ähnlich sein (ScHuERMANN 1958). Eitrige Gingivitiden und Ulcerationen des Zahnfleisches sind selten. Die rötlichen bis bräunlichen fleckförmigen Enantheme werden z. T. polsterartig erhaben. Peritonsilläre Ödeme und ödematöse Schwellungen der Uvula werden bei etwa $2 \%$ der Patienten beobachtet (sehr selten: Glottisödem).

\section{d) Differentialdiagnose}

Die Mononucleosis infectiosa ist durch eine starke Variabilität der Symptome ausgezeichnet. RoMrvGER (1955) unterscheidet 5 Verlaufsformen der Krankheit:

1. Das eigentliche Pfeiffersche Drüsenfieber (lymphämoides Drüsenfieber: GLanzmanN 1952) mit generalisierten Lymphknotenschwellungen.

2. Die Anginose, meist mit Pseudomembranen, also diphtherieähnlichen Bildern.

3. Die rein febrile Form mit einem typhusähnlichen Krankheitsbild.

4. Die cerebral-meningitische Verlaufsform.

5. Die hepatitische Form.

Aus dieser Aufstellung ergibt sich der Ansatz für die Differentialdiagnose. Bei Vorliegen eines Exanthems müssen Masern, Röteln (Lymphknotenschwellungen!) und Scharlach ausgeschlossen werden (bei letzterem: Auslöschphänomen). Typisch für die Mononucleosis infectiosa ist das Zusammentreffen der drei folgenden 
Symptome: Klinisches Bild mit Fieber, Kopfschmerz und vergrößerten Lymphknoten, Blutbild mit über 50\% Lymphocyten und monocytoiden Zellen sowie die positive heterophile Antikörper-Reaktion nach PAUL und BUNNEL, die nach Absorption mit Meerschweinchenniere einen Mindesttiter von 1:128 haben soll. Keines der drei Symptome ist spezifisch. Charakteristisch aber ist ihr gemeinsames Auftreten (Hoagland 1957).

Abgetrennt werden muß häufig eine Diphtherie (Erregernachweis) und eine Plaut-Vincent-Angina (Flora mit Spirillen und fusiformen Stäbchen). Auch an eine Lues II muß gedacht werden (bei der Mononucleosis infectiosa gibt es unspezifisch positive Wassermann-Reaktionn, daher Wiederholung der Seroreaktionen, möglichst Nelsontest und Spirochäten-Eiweißreaktion!).

Bei sehr schweren Verläufen müssen Sepsis, Tularämie und lymphatische Leukämie ausgeschlossen werden (serologische Differenzierung nach WöLLNER, Leberpunktion, Blutbildkontrollen). Über die monocytoiden Zellen (auch: Lymphoidzellen), die als Zwischenstufen zwischen den großen Lymphocyten und den Plasmazellen anzusehen sind, s. bei SIEde (1949): „Die Mononucleose bei Viruskrankheiten" (Zellen dieser Art bei Hepatitis epidemica, Viruspneumonie und Mononucleosis infectiosa).

Die Differentialdiagnose gegenüber der Hepatitis epidemica stützt sich auf die Paul-Bunnel-Reaktion und evtl. auf die Leberpunktion. Die Abtrennung der Mononucleosis infectiosa von der Hodgkinschen Lymphogranulomatose kann bei älteren Patienten - (Fitz-HugH 1957 beschrieb eine Mononucleosis infectiosa bei einer 64jährigen Frau) - und bei längerem Verlauf schwierig sein. Beim Morbus HoDGKIN sind gelegentlich Heteroagglutinine gefunden worden, die meistens durch die Differential-Absorption Davidsohns als Forssmann-Antikörper zu erkennen waren: Absorption durch Meerschweinchenniere, dagegen nicht durch Rindererythrocyten. KenIs $u$. Mitarb. (1958) konnten das seltene Zusammentreffen eines Morbus HodGKIN mit einer Mononucleosis infectiosa bei einem 22jährigen Mädchen beobachten. Bei derartigen Fällen empfiehlt sich die histologische Untersuchung eines exstirpierten Lymphknotens.

Zur Serologie der Mononucleosis infectiosa sei nachgetragen, daß die in der Regel (schon in den ersten 2 bis 3 Wochen) nachweisbaren Schafzell-Heteroagglutinine sich von den in jedem Serum vorhandenen Forssmann-Antikörpern dadurch unterscheiden, daß die Mononucleosis infectiosa-Agglutinine nicht durch Meerschweinchennierenzellen, wohl aber durch Rindererythrocyten absorbiert werden. In den letzten Jahren wurden weitere serodiagnostische Verfahren entwickelt, z. B. der Differentialtest mit papainisierten Schaferythrocyten (WöLLNER 1956) und der Nachweis von Rindererythrocyten-Hämolysinen sowie eine Komplementbindungsreaktion mit Rindererythrocyten-Lipoidextrakt (MÜLLER 1958). Diese Tests sind alle nicht spezifisch, wohl aber charakteristisch. Auf Einzelheiten kann hier nicht eingegangen werden. Verwiesen sei nur noch auf die interessanten Untersuchungen von SPRINGER (1957) über die Freisetzung des heterogenetischen „Mononucleosefaktors“ von Schaferythrocyten durch Influenzavirus und Pflanzenproteasen.

\section{e) Ätiologie, Pathogenese, Therapie}

Endgültig geklärt ist die Ätiologie der Mononucleosis infectiosa noch nicht. Viele Autoren nehmen an, daß ein Virus das ursächliche Agens darstellt. Gedacht wurde z.B. an eine Virusart aus der Gruppe der Adenoviren. Trautmann (1954) sah andererseits grippevirusähnliche, unterschiedlich große, runde Körperchen auf den Erythrocytenmembranen im Blut eines Mononucleosis infectiosa-Patienten, die elektronenoptisch sehr deutlich analysierbar waren. Dieser morpholo. 
gische Befund darf, so interessant er ist, nicht überbewertet werden (Verwechslung mit den Granula der Reticulocytenmembran evtl. möglich).

Das Agens der Mononucleosis infectiosa vermehrt sich nicht auf der Chorionallantoismembran von Bruteiern und kann nicht auf kleine Laboratoriumstiere übertragen werden. Beweisende Resultate z. B. mit der modernen ZellkulturTechnik stehen noch aus.

VAN Den Berghe und Liessens (1939), Sohier u. Mitarb. (1940) sowie Wising (1942) gelang es, unter Benutzung verschiedener Übertragungsmethoden sowohl mit Blut als auch mit Suspensionen aus dem Gewebe geschwollener Lymphknoten bei Cynomolgus- und Cercopithecusaffen ein der Mononucleosis infectiosa ähnliches Krankheitsbild hervorzurufen (buntes Blutbild mit monocytoiden Zellen, z. T. auch heterophile Antikörper im Blutserum, Titer von 1:128). Bei einigen Versuchsreihen war es möglich, das infektiöse Agens bis zu 10 Affenpassagen fortzuführen. Die Übertragung vom Menschen auf den Affen ließ sich z. T. auch mit filtriertem Material vornehmen.

WIsIng (1942) übertrug Blut von Mononucleosis infectiosa-Kranken auf 5 freiwillige Versuchspersonen. Von letzteren erkrankte nur ein Patient einwandfrei an Mononucleosis infectiosa (aus diesen Versuchen, Laborinfektionen und Beobachtungen während Epidemien wird die Inkubationszeit der Mononucleosis infectiosa mit durchschnittlich 7 bis 8 Tagen, Grenzen: 3 bis 20 Tage, errechnet). Das Agens der Mononucleosis infectiosa befällt ganz überwiegend die Zellen des reticulohistiocytären Systems in den Lymphknoten, der Milz und der Leber. Bei der manifesten Krankheit handelt es sich zunächst um einen Reizzustand des lymphoreticulären Gewebes (Punktionen von Lymphknoten, Milz, Leber und Knochenmark), an den sich ein proliferativer Prozeß anschließt. Hierbei werden vermutlich überstürzt gebildete, nicht ausgereifte "lymphoide" und „monocytoide“ Zellen in das periphere Blut ausgeschwemmt. Die Heilung der Mononucleosis infectiosa benötigt 2 bis 4 Wochen, gelegentlich mehrere Monate. Die Prognose ist im allgemeinen günstig, Todesfälle (z.B. durch Milzruptur oder Atemlähmung) sind selten.

LyoN (1957), der dem Fragenkomplex „Viruskrankheiten und Hyperergie“ besondere Aufmerksamkeit schenkt, weist auf die Beobachtung von PELnER und WaLdmax (1950) hin, die bei ihren Fällen von Mononucleosis infectiosa eine allergische Familiengeschichte oder eine allergische Erkrankung bei den Patienten selbst eruierten. Diese Autoren faßten die Mononucleosis infectiosa als eine Viruskrankheit auf, bei der das lymphatische System als Schockorgan reagiert.

Ein Spezificum gegen die Mononucleosis infectiosa gibt es noch nicht. Symptomatische Therapie mit Butazolidin, Calcium, Vitamin C, Kreislaufmitteln und Mundpflege, z. B. mit Trypaflavinlösung. Antibiotica und Sulfonamide sind bei bakterieller Sekundärinfektion indiciert. Der Nutzen von Gammaglobulinen, Cortison und ACTH (einige Erfolgsmeldungen!) ist noch umstritten.

Auf klinische Details kann hier nicht eingegangen werden; s. die Arbeiten von LÜDIN (1948), Tobiasch und Hörner (1952), Bender (1956), Dahl (1956), Shiver u. Mitarb. (1956), Smith (1956), Bredemann (1957), KrotaEr (1957), Clémençon und KrebsoH (1958), Hädpler (1958), Rollwagen (1958), AmanN (1959), Schindlbeck (1959) und ANETsberger (1960); weitere Literaturhinweise u.a. bei der zuletzt genannten Autorin.

\section{Haut- und Schleimhautbeteiligung bei der Poliomyelitis und der Polio-Schutzimpfung}

Die Poliomyelitis ist eine kontagiöse Viruskrankheit, die in der ganzen Welt verbreitet ist, en- oder epidemisch auftritt, überwiegend Kinder oder jugendliche Erwachsene befällt und für die Meldepflicht besteht. Das Poliomyelitisvirus hat 
drei Haupttypen (I: Typ Brunhilde, II: Typ Lansing und III: Typ Leon). Es ist sehr klein (10 bis $20 \mathrm{~m} \mu$ ) und kann nur in Speziallaboratorien gezüchtet werden. Klinisch verläuft die Poliomyelitis überwiegend unter dem Bilde eines banalen Infektes (inapparente bzw. Abortiv-Form), seltener mit den Symptomen einer aseptischen Meningitis (aparalytische Verlaufsform), und nur in Ausnahmefällen führt sie zur Ausbildung von schlaffen Lähmungen (paralytische Form) und evtl. zum Tode (GERMER 1954).

Im Frühstadium der Poliomyelitis können Enantheme beobachtet werden, die - worauf RATschow (1954) besonders hinwies - große Bedeutung besitzen. Werden sie in Epidemiezeiten diagnostiziert, so sind sie ein ,Signal zur Dispositionsprophylaxe" (Einhalten von Bettruhe). Es handelt sich hierbei um weißlichgraue Flecken (,lymphocytäre Proliferationen“), die in der Übergangszone vom weichen zum harten Gaumen lokalisiert sind. SchuERManN (1958) erwähnt außerdem das in Dreiecksform am harten Gaumen auftretende Enanthem von THrele. Oft finden sich als Prodrome bei der Poliomyelitis katarrhalische Erscheinungen (Rhinitis, Pharyngitis, Tonsillitis) und später die sog. „Facies poliomyelitica“, die durch das kongestionierte Aussehen mit leichter Cyanose der Wangen und Lippen sowie durch das blasse Munddreieck zustande kommt.

Nach der Poliomyelitis-Schutzimpfung mit der Salkschen Vaccine ist nur in einem sehr geringen Prozentsatz mit dem Auftreten von Hauterscheinungen zu rechnen. Der Impfstoff enthält außer dem Virus noch Antibiotica, Proteine, Phenolphthaleïn, Formaldehyd und Konservierungsmittel. Trotz der Massenimpfungen von Kindern und Erwachsenen in den USA und anderen Teilen der Welt sind Hautreaktionen nur selten beobachtet worden. STRoud u. Mitarb. (1957) sahen z. B. unter Hunderten von Geimpften nur 12mal urticarielle, ekzemähnliche oder psoriasiforme Exantheme ohne ernstere Begleitsymptome, die sich nach kurzer Bestandsdauer spontan zurückbildeten. Auch gegen Penicillin empfindliche Individuen und Psoriatiker konnten unbedenklich geimpft werden.

Callomon (1959) hob den von Czervinsky (1957) beobachteten Fall hervor, der schwere Veränderungen zeigte. Bei einem neunjährigen Mädchen, das mit $1 \mathrm{~cm}^{3}$ Salkscher Vaccine geimpft worden war, entwickelte sich zwei Wochen post vaccinationem unter Pruritus ein erythematöses Exanthem, das von den Oberschenkeln auf die Brust- und Bauchhaut sowie auf die Hände übergriff. Langsame Rückbildung unter Antihistamingaben. Nach 5 Wochen erfolgte die zweite Impfung $\left(0,1 \mathrm{~cm}^{3}\right.$ Vaccine). Nach 5 Tagen: generalisierter, heftiger Juckreiz, Schmerzen in den Kniegelenken und ein Exanthem in der Schultergegend. Nach weiteren 24 Stunden: generalisiertes Exanthem (,leicht erhabene Erythemflächen“), Schwellung der Augenlider, doch kein Fieber. Später: deutliche exsudative Komponente des Ausschlages. Heilung erst nach Prednisontherapie.

\section{Haut- und Sehleimhautveränderungen bei einigen tropischen bzw. subtropischen Viruskrankheiten ${ }^{1}$}

In den Tropen und Subtropen, z. T. auch in den mediterranen Klimazonen, kommen Viruskrankheiten von besonderer Natur vor. Letztere besteht vor allem darin, daß diese Infektionskrankheiten nicht unmittelbar kontagiös sind. Die Virusarten, die sie hervorrufen, werden nicht ausgeschieden und finden sich weder auf der Hautoberfläche noch auf den Schleimhäuten vor. Thre Übertragung wird nicht direkt, sondern nur durch blutsaugende Insekten vollzogen. Diesem Über-

${ }^{1}$ Vgl. mit diesem Kapitel auch den Beitrag von R. D. G. PH. Stmons, Amsterdam, über die nichtvenerischen tropischen Infektionskrankheiten in diesem Ergänzungswerk: Band IV, Teil 1. 
tragungsmodus ist ein besonderer Infektionsverlauf zugeordnet. Das Virus ist in einer bestimmten Krankheitsphase in großen Mengen im Blut angereichert. Hierdurch wird den Insekten die Aufnahme des Virus (durch den Stich) ermöglicht. Dem kurzen Infektionsstadium, in dem es zur Ausbreitung der Viren auf dem Blutwege kommt, folgt in der Regel nach einigen Tagen das Stadium der Reaktion. Das Virus verschwindet nun aus dem peripheren Blut und die Symptome der Infektion klingen dann entweder schnell $a b$, oder es schließt sich eine Phase der Organmanifestation an (mit mehr oder weniger stark ausgeprägten degenerativen Veränderungen der inneren Organe, die z. B. beim Gelbfieber rasch den Tod herbeiführen können). Der akute, zeitlich normierte, kurzfristige Verlauf der fieberhaften Erkrankungen beruht auf Immunitätsvorgängen, die bereits frühzeitig in Erscheinung treten. Sie werden durch die Bildung spezifischer Antikörper bedingt und führen zu einer meist langdauernden, beim Gelbfieber z. B. lebenslänglichen Immunität (NAUCK 1952 und 1956).

Die tropischen bzw. subtropischen Viruskrankheiten, zu denen vor allem Gelbfieber, Dengue, Pappataci- und Rifttal-Fieber zählen, treten en- oder epidemisch auf. Nach NAUCK (1956) hängt ihre Verbreitung von folgenden Faktoren ab:

1. Vorhandensein eines Virusreservoirs (Mensch oder Tier).

2. Vorkommen geeigneter, zu den Stechmücken gehörender Überträger in einer für die Übertragung ausreichenden Dichte.

3. Temperaturhöhe und Luftfeuchtigkeit, die eine Vermehrung des Virus im Überträger ermöglichen - und

4. Empfänglichkeit der Bevölkerung in Abhängigkeit von der Immunitätslage Grad der Durchseuchung, Impfschutz).

\section{a) Dengue}

\section{a) Synonyma und Definition}

Das Denguefieber (break-bone fever, dandy fever, denguerro, joint fever, bouquet fever, giraffe fever, polka fever, Knöchel-, Fünf- oder Siebentagefieber) ist eine kurzfristige, durch Stechmücken (Aëdes) übertragene, akute, epidemisch auftretende, gutartig verlaufende Viruskrankheit des Menschen, die durch Fieber von 5- bis 7 tägiger Dauer, Muskel- und Gelenkschmerzen, ein morbilli- oder scarlatiniformes Exanthem, durch Lymphknotenschwellung und Leukopenie gekennzeichnet ist. Im Gegensatz zum Gelbfieber, das durch die gleiche Mückenart (Aëdes aegypti) übertragen wird, tritt das Denguefieber in weitaus mehr Ländern auf, ist aber durch die Übertragungsart (genau wie das Gelbfieber) an die wärmeren Zonen gebunden (NAUCK 1952, GERMER 1954).

\section{ß) Klinik und Differentialdiagnose}

Nach 5 - bis 8tägiger Inkubation (Grenzen : 3 bis 15 Tage) beginnt die Krankheit mit Kopf-, Muskel- und Gelenkschmerzen sowie mit plötzlichem Temperaturanstieg (Bradykardie!). Mitunter tritt bereits am ersten Krankheitstage außer der Fieberrötung des Gesichtes und einer Conjunctivitis ein initiales, roseoliformes, Rash-artiges, sehr flüchtiges Exanthem auf (zuweilen auch Schüttelfrost). Nach zwei bis dreitägigem Fieber $\left(39-40^{\circ} \mathrm{C}\right)$ fallen die Temperaturen für 2 bis $2^{1} / 2$ Tage ab (nicht ganz bis zur Norm) und am 5. Krankheitstag erfolgt ein neuer Anstieg (meist bis $40^{\circ} \mathrm{C}$ ). Am 6. oder 7. Tage tritt kritische Entfieberung ein.

Das für Dengue kennzeichnende maculopapulöse Exanthem entwickelt sich am 3. bis 5. Tage. Es ist von kurzer Bestandsdauer und klingt meist schon nach 2 bis 3 Tagen wieder ab. Es befällt Hände, Füße, Gesicht, Hals, Brust, Bauch und Rücken. Juckreiz stellt sich besonders an den Händen und Fußsohlen ein. Das 
Exanthem ist vielgestaltig und untersehiedlich stark ausgeprägt (es fehlt aber nur selten). Es kann morbilli- oder scarlatiniform, aber auch urticariell sein. Das Gesicht bleibt häufiger frei. Auf Druck blassen die Hauterscheinungen ab. Es kann (keineswegs immer!) kleieförmige Schuppung im Stadium der Abheilung eintreten. Im allgemeinen ist die Blutungsneigung nicht oder nicht stark vorhanden. Bei manchen Epidemien wurden jedoch - häufig erst am letzten Fiebertage - kleine Petechien im Bereich von Fuß- und Handrücken, Achseln, Genitale und Mundschleimhaut beobachtet. Selten entwickelt sich eine Orchitis. Typisch sind das schwere Krankheitsgefühl, die verzögerte Rekonvaleszenz und die Schmerzen in den Kniegelenken, die das Gehen behindern (Dengue $=$,Dandy", wegen des eigenartig gespreizten Ganges). Die Milz ist nicht geschwollen, hingegen sind die Lymphknoten häufiger vergrößert. Schon in den ersten 24 Std der Krankheit findet sich eine Leukopenie (relative Granulocytose). In der ersten Fieberperiode können profuse Schweißausbrüche entstehen (eigentümlich süßlichfauliger Geruch). Die Prognose ist überwiegend gut, Todesfälle sind Ausnahmen. $\mathrm{Zu}$ den selteneren Komplikationen zählen: Magen- und Darmblutungen, Meningitis, Thrombophlebitis, Parotitis, Polyneuritiden, Keratitis und Iritis. Weitere Angaben über die Klinik s. bei NAUCK (1952).

Differentialdiagnostisch müssen zu Beginn der Erkrankung Grippe, Pappatacifieber, Malaria und Fleckfieber berücksichtigt werden. Das Dengue-Exanthem muß von den bei Masern, Röteln und Scharlach auftretenden Hauterscheinungen abgegrenzt werden, was nicht immer leicht ist (Bestandsdauer, Auslöschphänomen, Blutbild, Begleitsymptome, epidemiologische Gesichtspunkte). Im Beginn der Krankheit ist mitunter eine Abtrennung von Gelbfieber notwendig (Ikterus kann bei Gelbfieber fehlen, andererseits kann hin und wieder bei Dengue ein Ikterus vorkommen).

Das Überstehen von Dengue hinterläßt nicht so langdauernde Immunität wie das Gelbfieber (meist nur Immunität für ein Jahr).

Die Therapie besteht, da kein Spezificum bekannt ist, in Bettruhe und der Verabfolgung von Kreislaufmitteln und Salicylaten (auch Phenacetin, Pyramidon oder Irgapyrin).

Anläßlich von seltenen Todesfällen erhaltene Seltionsbefunde wiesen degenerative Schäden des Capillarendothels, mehr oder weniger ausgedehnte Blutungen im Endo- und Perikard, in der Pleura und im Peritonaeum, in den Schleimhäuten des Magen- und Darmkanals, in der Haut, in den Muskeln und im ZNS auf (NAUCK 1952). Beschrieben wurde außerdem eine granulomatöse Thrombophlebitis in der Subcutis (ähnlich wie bei der Thrombophlebitis migrans), die sich mehrere Wochen nach Krankheitsbeginn ausbildete.

SABIN (1948) untersuchte die Histologie von Hautveränderungen, die nach intracutaner Injektion von Denguevirus und nach petechialen Blutungen auftraten. SABIN sah weder allgemeine Alterationen der Epidermis noch Einschlußkörper in den Epithelzellen. Dagegen konnte regelmäßig eine deutliche Gefäßreaktion mit Endothelschwellung, perivasculärem Ödem und Infiltration mit mononucleären Zellen beobachtet werden. In der Umgebung der Petechien gibt es keine nennenswerten entzündlichen Veränderungen. Werden 0,1 bis $0,2 \mathrm{~cm}^{3}$ menschliches Serum, das Denguevirus enthält, bei empfänglichen Personen intracutan injiziert, so bilden sich nach 3 bis 5 Tagen eine lokale Rötung und ein Ödem mit einem Durchmesser von 1 bis $4 \mathrm{~cm}$ an der Injektionsstelle aus (SABIN 1952, SORRELL 1956).

Über Maßnahmen zur Seuchenbekämpfung und über die Dengue-Prophylaxe s. bei Nadck $(1952,1956)$. Der von SabiN und Schlesinger (1945) eingeführte 
Impfstoff aus mäuseadaptierten Denguestämmen hat sich als wirksam erwiesen (Impfungen in Epidemiezeiten vor allem für Reisende und Einwanderer).

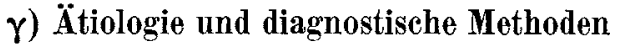

Die Virusätiologie des Denguefiebers wurde bereits 1907 von AshburN und CraIg (Philippinen) erkannt. Die Elementarkörper-Größe des Denguevirus beträgt 17-25 $\mathrm{m} \mu$ (Bestimmung durch Ultrafiltration mittels Gradokolmembranen). Es gibt mindestens zwei (möglicherweise drei oder mehr) immunologisch differente Typen des Virus. Serologisch ist der Erreger des Denguefiebers mit dem Gelbfiebervirus, dem West-Nil- und dem Virus der japanischen B-Encephalitis verwandt (Untersuchungen mit Hilfe der Komplementbindungsreaktion).

Das Denguevirus kann auf die üblichen kleinen Laboratoriumstiere nicht übertragen werden. Infizierte Affen erkranken nur inapparent. - Durch besondere Versuchsanordnung (intracerebrale Injektion, Fortführung in Hirnpassagen, Infektion möglichst junger Tiere) kann das Denguevirus auf Mäuse übertragen werden (Sabin und Schlesinger 1945, Gordon-Smith 1956). Die Adaptation des Virus an Mäuse bedingt eine Änderung der pathogenen Eigenschaften. Schon nach 7 Passagen tritt nach Rückimpfung auf den Menschen keine typische DengueErkrankung mehr auf, doch entwickelt sich trotzdem eine kräftige Immunität (Schutzimpfungen mit mausadaptiertem Virus). Die Züchtung des Denguevirus auf Mäusen hat auch diagnostische Bedeutung, da sie die Durchführung von Neutralisationstests ermöglicht (Mäuseschutzversuch mit Patientenserum ähnlich wie bei der Gelbfieberdiagnose). Details s. bei SabIN (1955).

Es wurde nachgewiesen, daß 24 Std nach Beginn des Fiebers das Serum von experimentell mit Dengue infizierten Personen 1 Million M.I.D. (MinimalInfektions-Dosen für den Menschen) Denguevirus pro $\mathrm{cm}^{3}$ enthält (Einzelheiten s. bei NaUck 1952).

HotTA und Evans (1956) gelang es, mäuseadaptierte Stämme des Denguevirus (Typ 1 und 2) in Zellkulturen von Affennierengewebe zu züchten (ausgesprochener cytopathogener Effekt).

Aus infizierten Säuglingsmäusen gewonnene Hirnextrakte vermögen unter definierten Versuchsbedingungen, die für Typ 1 und Typ 2 des Denguevirus verschieden sind, Hühnererythrocyten zu agglutinieren (SWEET und SABIN 1954). Hierbei spielen der pH-Wert, die Temperatur und die Zahl der Passagen eine wesentliche Rolle. Diese Methode ermöglicht auch (unter Verwendung von Patientenseren) die Durchführung eines Hämagglutinations-Hemmtests (Bestimmung des Hemmtiters im Rekonvaleszentenblut). Die Laboratoriumsdiagnose der Dengue ist nicht einfach und bleibt vorerst nur Speziallaboratorien vorbehalten.

\section{b) Pappatacifieber}

Das Pappatacifieber (Phlebotomus-Fieber, Sandfly-fever, Dreitagefieber, Hundskrankheit, Sommerfieber) ist eine stets gutartige, akute Viruskrankheit des Menschen, die durch Phlebotomus papatasii übertragen wird und die meist mit dreitägigem Fieber, Kopfschmerz, Augendruck, Conjunctivitis sowie mit starker Beeinträchtigung des Allgemeinbefindens und Leukopenie einhergeht. Trotz der an sich guten Prognose kann die Rekonvaleszenz lange andauern. Das Wort „Pappataci" ist italienisch und bedeutet „stiller Fresser". Das Pappatacifieber kommt nur in Gegenden vor, in denen Phlebotomus papatasii zu Hause ist, insbesondere in Ländern, die zwischen $20^{\circ}$ und $45^{\circ}$ nördlicher Breite in Europa, Asien und Afrika liegen (s. ausführlich bei NAUck 1952).

Nach einer Inkubationszeit von 3-6 Tagen setzt plötzlich Fieber ein $\left(39^{\circ}\right.$ bis $40^{\circ} \mathrm{C}$ ). Es besteht ein sehr starkes Krankheitsgefühl mit Stirnkopfschmerz, 
Brennen und Druckschmerz in den Augen (diagnostisches „Dreifingerzeichen“: Mittelfinger im Bereich der Nasenwurzel aufstützen, mit Zeige- und Ringfinger vorsichtig beide Bulbi palpieren = Druckschmerz!), Lichtscheu, Steifheit im Nacken und im Rücken, mit ziehenden Schmerzen in den Extremitäten und stark gerötetem Gesicht (Nauck 1952, Pierrou 1957). Die Conjunctiven sind stark injiziert, mitunter in Streifenform im Bereich der Lidspalte. Auch Augenhintergrundsveränderungen kommen vor (Plasmaaustritte aus den Retinagefäßen, Details s. bei Krauss 1955). Gelegentlich werden Halsschmerzen mit starker Rachenrötung, weiter Durchfälle (evtl. mit Blutbeimengung), Nasenbluten, Erbrechen und Schwindel beobachtet. Milz, Leber und Lymphknoten sind nicht angeschwollen. Das Blutbild zeigt eine ausgesprochene Leukopenie.

Der Fieberverlauf ist nicht ganz einheitlich. Meist steigt die Temperatur plötzlich an, geht am 2. und 3. Tage etwas zurück und sinkt am 4. Tage ganz bis zur Norm ab (Bradykardie; Verf. sah 1943/44 auf dem Balkan, vor allem in Albanien und Montenegro, gelegentlich kurze Fieberrückfälle im Verlauf der ersten beiden Krankheitswochen). - Die Haut ist insgesamt trocken, fühlt sich heiß an und ist gerötet (leichte Hyperämie, kein eigentliches Exanthem). Häufig lassen sich noch die etwas irritierten Stichstellen der Phlebotomen erkennen. Nur ausnahmsweise entwickeln sich diffuse Erytheme oder roseoliforme Exantheme. Mitunter treten urticarielle Veränderungen, Petechien und Erscheinungen im Sinne eines Erythema exsudativum multiforme auf. Niemals aber entsteht ein so charakteristisches Exanthem wie beim Denguefieber (NAuck 1952). Die Rekonvaleszenz ist von sehr verschiedener Dauer (leichter Verlauf von wenigen Tagen bis zu schlechtem Allgemeinbefinden über mehrere Wochen). Die Letalität ist praktisch gleich Null. Kinder unter 5 Jahren erkranken weniger häufig und leichter (Guelmino und JeVTIC 1955).

Differentialdiagnostisch kommt vor allem das Denguefieber in Betracht (nicht so stark ausgeprägte Bradykardie, längerer Fieberverlauf, meistens vorhandenes typisches Exanthem). Auch Grippe (meist mit mehr katarrhalischen Erscheinungen), Malaria, Rückfallfieber und Fleckfieber müssen bei der Differentialdiagnose berücksichtigt werden (Details bei NAUCK 1952).

Die Therapie ist rein symptomatisch (s. den Abschnitt Dengue). Die Prophylaxe des Pappatacifiebers richtet sich ausschließlich gegen den Überträger (Insektizide: DD'T-haltige Mittel).

Filtrationsversuche mit Gradokolmembranen ergaben, daß das PappataciVirus Elementarkörper mit Durchmessern zwischen 40 und $60 \mathrm{~m} \mu$ haben muß. Nach den bisherigen Untersuchungen scheint der Mensch der einzige Wirt für das Pappataci-Virus zu sein (Übertragungsversuche von Mensch zu Mensch mit Freiwilligen). Es gibt mehrere immunologisch differente Virusstämme (Zweitinfektionen mit anderen Virusstämmen sind möglich).

\section{c) Gelbfieber}

NAUCK (1952) definiert diese Viruskrankheit folgendermaßen: „Das Gelbfieber ist eine in bestimmten Gebieten der Tropenzone heimische akute Infektionskrankheit, die durch Stechmücken übertragen wird (Aëdes aegypti). Die durch ein Virus hervorgerufene Erkrankung geht bei schwerem Verlauf mit Fieber, Gelbsucht, Albuminurie und Blutungen einher und ist von einer bleibenden Immunität gefolgt. Häufig verläuft die Infektion in milder Form oder ohne klinische Manifestationen."

Auf das klinische Bild des Gelbfiebers (Yellow fever, Fièvre jaune, Dschungelfieber) kann hier nicht näher eingegangen werden (s. bei NAUCK 1952, 1953, 1956 
und bei GERMER 1954). Hier können nur einige Veränderungen berücksichtigt werden, die den Dermatologen interessieren.

Die Inkubationszeit des Gelbfiebers beträgt 3 bis 6 Tage. Die Krankheit nimmt einen Verlauf, der in drei Phasen eingeteilt werden kann:

1. Initiales Fieber (Infektionsperiode),

2. Kurzes, nicht stets vorhandenes Stadium der Remission - und

3. Periode der Reaktion und der Organschädigungen.

\section{a) Haut- und Schleimhauterscheinungen}

Als Prodrome sieht man u. a. Trockenheit und Rötung der Haut, Conjunctivitis und Lichtscheu. Die Zunge kann anfangs etwas gerötet sein, später wird sie „,trocken, belegt, klein und spitz" (im Gegensatz zu der geschwollenen, weichen Malaria-Zunge). Gaumen und Zahnfleisch röten sich, schwellen ödematös an und zeigen Blutungstendenz. In der dritten Periode der Organschädigung nehmen Skleren und Haut eine gelbliche Färbung an, die sich ,zu einem intensiven Ikterus steigert" (hellgelber oder mehr schmutzig-gelber Farbton; die Intensität der Gelbsucht ist unterschiedlich stark). NAUCK (1952) betont, daß eine charakteristische Hauteruption fehlt, doch gelegentlich erythematöse oder petechiale Veränderungen beobachtet werden können.

Die Diagnose des Gelbfiebers beruht auf folgenden Laboratoriumsuntersuchungen:

1. Isolierung des Virus (Beimpfung von Affen, intracerebrale Infektion von Mäusen). Virusgröße: $17-28 \mathrm{~m} \mu$.

2. Nachweis spezifischer Antikörper (Mäuseschutzversuch: Beimpfung der Tiere mit einer Mischung von neurotropem Gelbfiebervirus und dem zu untersuchenden Serum. Bei Vorhandensein von Immunkörpern im Serum bleibt eine Infektion aus, fehlen diese, so haftet das Virus im ZNS und führt den Tod der Tiere herbei.)

3. Histopathologische Untersuchungen bei tödlich verlaufenen Fällen (charakteristische Leberveränderungen).

\section{ß) Allergische Reaktion nach Gelbfieberimpfung}

Die Gelbfieberimpfung ist eine aktive Schutzimpfung, die in der Regel sehr gut vertragen wird. Geimpft wird mit einer Vaccine, die den 17 D-Stamm enthält. Bei diesem Stamm des Gelbfiebervirus handelt es sich um eine Virusart, die im Verlauf von Züchtungsversuchen in Gewebekulturen aus Hühnerembryonalgewebe gewonnen wurde. Der 17 D-Stamm erwies sich bei Erhaltung der immunisatorischen Eigenschaften als so stark abgeschwächt, daß er gefahrlos zu Impfzwecken verwendet werden konnte.

Allergische Reaktionen im Anschluß an die Gelbfieberimpfung treten nur sehr selten auf. SulzBerger und Asher (1942) berichteten über drei Fälle von Urticaria und über Hauterytheme vom Typ des Erythema exsudativum multiforme. Auch Asthmaanfälle, Dyspnoe, Gesichtsödem und gleichzeitig Urticaria generalisata kommen ausnahmsweise (möglicherweise Allergie gegen Hühnereiweiß!) vor. BeCKer und Lieske (1957) beobachteten 6 Std post vaccinationem eine sehr schwere Impfkomplikation. Es bildeten sich Fieber, Schüttelfrost und Myalgien und $14 \mathrm{Std}$ später ein schwerer Kollaps mit nachfolgender Polyarthritis einschließlich Kniegelenkergüssen von mehr als 6wöchiger Dauer aus.

\section{d) Weitere tropische Viruskrankheiten}

Das Rifttalfieber (Rift Valley fever) wird durch ein Virus hervorgerufen, das der Gelbfieber-Dengue-Gruppe angehört. Beim Rifttalfieber kommt es nicht zur Ausbildung eines Exanthems (NAUCK 1952). Der Erreger dieser Erkrankung 
ruft in Zellkulturen (z.B. aus Mäuse- und Rattentumoren, auch aus menschlichem Embryonalgewebe) einen cytopathischen Effekt hervor, ähnlich wie z. B. das Gelbfiebervirus in HeLa-Zellkulturen.

In den letzten Jahren wurden mehrere neue tropische Virusinfektionen entdeckt, über die z. T. noch wenig bekannt geworden ist (Isolierungen aus Stechmücken, Affen- und Menschenblut). Diese Virusarten verhalten sich im Mäuseversuch neurotrop. Beim Menschen scheinen diese Infektionen überwiegend entweder inapparent oder subklinisch (leichte, uncharakteristische Krankheitsformen) zu verlaufen. U̇ber begleitende Haut- und Schleimhautveränderungen liegen bisher keine Daten vor. Die gefundenen Virusarten wurden nach ihren Fundorten oder nach dem Gattungsnamen der als Zwischenträger dienenden Steckmücken benannt. Es handelt sich um folgende Viren:

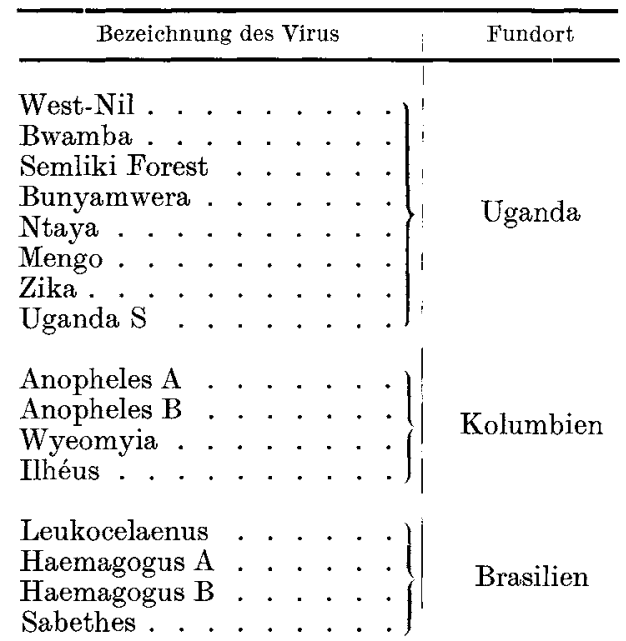

Es bedarf noch der Klärung, ob es sich bei diesen Virusarten um ,,vollwertige Erreger" oder um harmlose ,,saprophytische Virusformen" handelt (Details s. bei NAUCK 1956 und bei TAYLOR 1952).

\section{Maul- und Klauenseuche beim Menschen und Maul- und Klauenseuche-ähnliche Krankheitsbilder}

\section{Einleitung}

Die Maul- und Klauenseuche besitzt große volkswirtschaftliche Bedeutung, spielt aber in der Humanmedizin nur eine geringe Rolle. Durch manche Seuchenzüge kann der Rinderbestand beträchtlich gelichtet werden und der Schaden Millionenbeträge ausmachen. Menschliche Maul- und Klauenseuche-Infektionen kommen jedoch nur selten vor. Im Jadassohnschen Handbuch finden sich drei Abschnitte über die Maul- und Klauenseuche aus den Jahren 1930-1932, und zwar

1. von A. STÜHMER (1932) in Bd. II, S. 271-300 eine heute noch gültige Abhandlung über „Maul- und Klauenseuche beim Menschen“,

2. von W. JADASsOHN (1932) in Bd. II, S. 399-401 ein Abschnitt über die immunbiologischen Vorgänge in der Haut bei der Maul- und KlauenseucheInfektion und

3. von J. Heller (1930) ein Kapitel über die Maul- und Klauenseuche im Beitrag ,Die Klinik der wichtigsten Tierdermatosen“, Bd. XIV, Teil 1 (Maulund Klauenseuche: S. 828-830). 